Check for updates

Cite this: RSC Adv., 2019, 9, 25554

Received 15th April 2019

Accepted 2nd August 2019

DOI: $10.1039 / \mathrm{c} 9 \mathrm{ra02839k}$

rsc.li/rsc-advances

\section{Transition metal catalyzed [6 + 2] cycloadditions}

\author{
Amit Anand, *a Prabhpreet Singh, (D) ${ }^{b}$ Vipan Kumar (D) *b and Gaurav Bhargava (D) *c
}

The [6 +2] cycloaddition reactions are one of the important synthetic transformations to construct eight membered carbo-/heterocyclic systems. The present review is an attempt to update readers on transition metal catalyzed [ $6+2$ ] cycloaddition reactions of various $6 \pi$-contributing substrates such as cycloheptatrienes (CHT), cyclooctatetrenes (COTT), allenals, vinylcyclobutanones, fulvene etc. employing rhodium, cobalt, titanium, copper, platinum, ruthenium, rhenium and diphenylprolinolsilyl ethers etc. as catalysts. The transition metal catalyzed [6+2] cycloaddition reactions with a variety of functionalized substrates provide straightforward access to eight membered cyclic and/or 5/8, 6/8 etc. condensed carbo-/heterocyclic molecules in moderate to good yields.

\section{Introduction}

Cycloaddition reactions are considered to be one of the most powerful methods for the construction of cyclic skeletons ${ }^{1}$ with atom economy. There are ample reports on different variants of $[4+2]$ and $[3+2]$ cycloadditions which provide an easy access to a variety of five or six membered carbo-/heterocycles. ${ }^{2,3}$ However, the parallel methodologies such as $[5+2],{ }^{4}[6+2],{ }^{5}[8+$ $2]^{5 b}$ etc. for the synthesis of seven, eight or ten membered carbo-/heterocycles are still uncommon in the literature. Eightmembered rings are found in a wide variety of natural products and are useful ring systems available in variety of drugs, drug leads, or biological probes. ${ }^{6}$ Taxol, the well-known natural product in this family, is now among the most potent anticancer drug in clinical use. In 2008, another member of this family, pleuromutilin was approved for use as an antibiotic by Food and Drug Administration (FDA) ${ }^{7}$ (Fig. 1). Several methods ${ }^{8-12}$ including ring-closing metathesis and Cope rearrangement have been reported for the synthesis of eight-membered carbocycles..$^{13}$ However, the intolerance to substrate substituent in conventional procedures along with complexities observed in natural products makes these techniques ineffective and instigated the development of alternate protocols. Recent years have seen a significant upsurge in this direction with relatively few reports appearing on the synthesis of eight membered carbocycles using $[6+2]^{5,14}$ and $[4+2+2]^{11}$ cycloaddition reactions. Concerted $[6+2]$ cycloaddition reactions are forbidden thermally as per Woodward-Hoffmann rules, when the two reacting $\pi$-systems add in a suprafacial fashion. However, transition metal-catalyzed $[6+2]$ cycloadditions constitute one such

${ }^{a}$ Department of Chemistry, Khalsa College, Amritsar, 143005, Punjab, India. E-mail: aa_wiz@yahoo.com

${ }^{b}$ Department of Chemistry, Guru Nanak Dev University, Amritsar-143005, India

${ }^{c}$ Department of Chemical Sciences, IKG Punjab Technical University, Kapurthala, 144603, Punjab, India.E-mail: gaurav@ptu.ac.in; gauravorganic@gmail.com protocol for the synthesis of monocyclic or condensed functionalized cyclooctadienes. The present review summarizes various reports on the transition metal catalyzed inter- and intra-molecular $[6+2]$ cycloaddition reactions appeared in literature since $2000 .^{14}$

\section{Rhodium catalyzed [6 + 2] cycloadditions}

Rhodium complexes plays a pivotal role in organic synthesis as major catalytic contributors to $\mathrm{C}-\mathrm{C}$ bond formation reactions. ${ }^{15}$ A number of carbo-/heterocyclic systems have been generated employing rhodium complexes as efficient catalyst in a variety of cycloaddition/cyclization reaction ${ }^{16}$ Literature rationale suggests an inspiring advancement in this field and many research groups are extensively using rhodium complexes to efficiently conceive these reactions. ${ }^{17}$ Considering the importance of rhodium catalysed cycloadditions, there should have been a number of reports on generation of eight membered carbo-/heterocycles engaging rhodium complexes in [6+2] cycloadditions, however only a few reports are available which successfully comprehends $[6+2]$ cycloadditions. Till now, different substrates such as cycloheptatriene, 2-vinylcyclobutanones, allenals, allenylcyclobutanes, cyclooctatrienes etc. have been reported as $6 \pi$-components in $\mathrm{Rh}(\mathrm{I})$ catalysed $[6+$
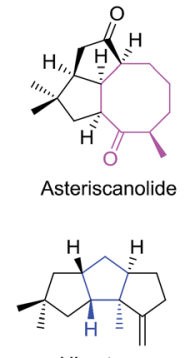

Hirsutene

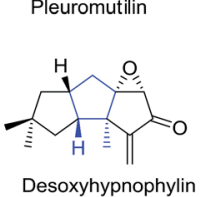

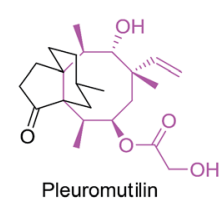
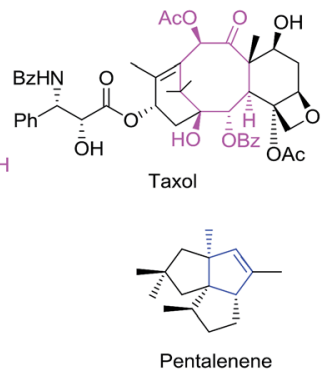

Fig. 1 Carbocycles in natural products. 
2] cycloadditions involving variety of alkene alkyne, allene as $2 \pi$-components to afford monocyclic/condensed eight membered carbocycles/heterocycles.

\section{Rh(I) catalysed [6 + 2] cycloadditions of 2-vinylcyclobutanones}

One of the earliest reports on Rh(I) catalyzed [6+2] cycloadditions of 2 -vinylcyclobutanones as $6 \pi$-components is reported by Wender et al. It involves intramolecular $[6+2]$ reactions of 2vinylcyclobutanones $\mathbf{1 a}-\mathbf{h}$ with tethered alkenes for the construction of eight-membered-ring systems $\mathbf{2 a - h} .^{18}$ The $[6+2]$ reactions has diverse substrate compatibility and proceed for a variety of different tethers to produce cis-fused condensed cyclooctatrienes $\mathbf{2 a - h}$ in excellent yields (Scheme 1).

The $[6+2]$ cycloadditions involve initial formation of a five membered metallacycle $\mathbf{A}$, which undergoes ring expansion to nine-membered metallacycle $\mathbf{B}$, demetallation of $\mathbf{B}$ affords eight-membered condensed carbocycles via reductive eliminations (Fig. 2).

\section{Rh(I)-catalyzed formal [6 + 2] cycloadditions of allenal}

Sato et al. have developed an efficient methodology for the synthesis of fused bicyclic ketones 4. It involves the Rh(I)-catalyzed intramolecular [6 +2] cycloadditions of alkyne/alkene tethered allenal 3a-j using Rh(I)-complex as catalyst. [Rh(IMes)(cod) $] \mathrm{ClO}_{4}$ is an effective catalyst in these $[6+2]$ cycloadditions. ${ }^{19}$ The use of other Rh(I) complexes as catalyst such as $[\mathrm{Rh}(\mathrm{IiPr})(\mathrm{cod})] \mathrm{ClO}_{4},[\mathrm{Rh}(\mathrm{IPr})(\operatorname{cod})] \mathrm{ClO}_{4}$ and $[\mathrm{Rh}(\mathrm{IMes})(\mathrm{cod})] \mathrm{ClO}_{4}$ afford bicyclic ketones in lower yields and $[\mathrm{Rh}(\mathrm{dppe})] \mathrm{ClO}_{4}$ is
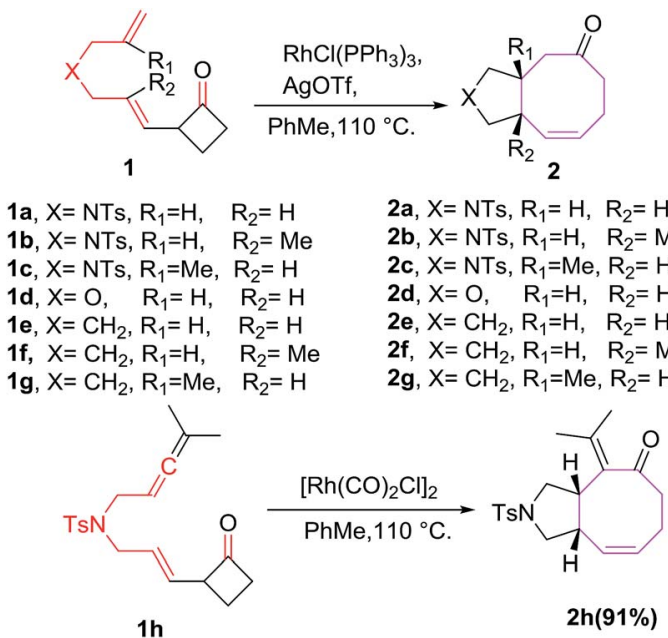

Scheme 1 Rh(1) catalysed [6 +2] cycloaddition reactions of tethered alkenes with cyclobutanones.

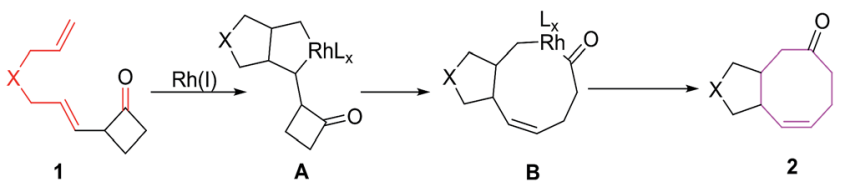

Fig. 2 Plausible mechanism for synthesis of eight-membered condensed carbocycles. completely ineffective in conceiving $[6+2]$ reactions. The $[6+2]$ cycloadditions using $\mathrm{RhCl}\left(\mathrm{PPh}_{3}\right)_{3}$ afford bicyclic ketone 4 in relatively good yield (72\%) but with longer time. The cyclizations of $\mathbf{3 a}$ and $\mathbf{3 b}$ having phenyl and TMS groups on the alkyne moiety provide $\mathbf{4 a}$ and $\mathbf{4 b}$ in $71 \%$ and $90 \%$ yields respectively. Substrate $\mathbf{3 d - f}$ containing a heteroatom in the chain afforded corresponding heterocycles $\mathbf{4 d - f}$ in good to excellent yields. Elongation of the tether between the alkyne and allene moieties by one carbon is well tolerated in the $[6+2]$ cycloaddition reaction and afford 6/8 fused bicyclic ketone $4 \mathrm{~g}$ in $70 \%$ yield as evident by the conversion of $\mathbf{3 g}$ to $\mathbf{4 g}$. The cyclizations of substrates $\mathbf{3 h}-\mathbf{i}$ having an tethered alkene also afford bicyclic ketones $\mathbf{4 h}-\mathbf{i}$ in a stereoselectively (Scheme 2).

The $[6+2]$ cycloaddition of enantiomerically enriched (S)-5 (94\% ee) yields cyclic ketone (S)-6 in high yields with reasonable transfer of chirality ( $86 \%$ ee) as shown in Scheme $3 .^{19}$

The possible mechanism for the formation of 6 involves the oxidative addition of $\mathrm{Rh}(\mathrm{I})$ complex to the $\mathrm{C}-\mathrm{H}$ bond of the aldehyde 5 followed by insertion of the $\mathrm{C}=\mathrm{C}$ bond of the allene to give oxo-rhodacycle $\mathbf{C}$ which undergoes isomerization to oxorhodacycle $\mathbf{C}$ via $\pi$-allylrhodium intermediate $\mathbf{F}$. Insertion of an alkyne or alkene into the $\mathrm{Rh}-\mathrm{C}$ bond followed by reductive elimination yields bicyclic ketone 4/6 (Fig. 3).

Sato et al. have also explored the intermolecular $[6+2]$ cycloadditions of 4-allenal 7 and alkyne 8, for the synthesis of functionalised monocyclic cyclooctane derivatives $\mathbf{9 .}^{20}$ The intermolecular $[6+2]$ cycloadditions suffer from unfavorable entropy disadvantage which resulted in decreased yield of the [6 +2 ] cycloadducts with the isolation of side products 10 through hydroacylation of allenal $7^{10 c}$ and formation of $\mathbf{1 1}$ by trimerization of alkyne 8 (Scheme 4).

The $\left[\mathrm{Rh}(\mathrm{SIMes})(\mathrm{cod}) \mathrm{ClO}_{4}\right.$ have been found to be efficient in conceiving intermolecular reactions with the selective formation of eight membered carbocycle 9 (68\%). The [Rh(IMes)(cod)] $\mathrm{ClO}_{4}$ as catalyst is non selective and afford mixture of eight

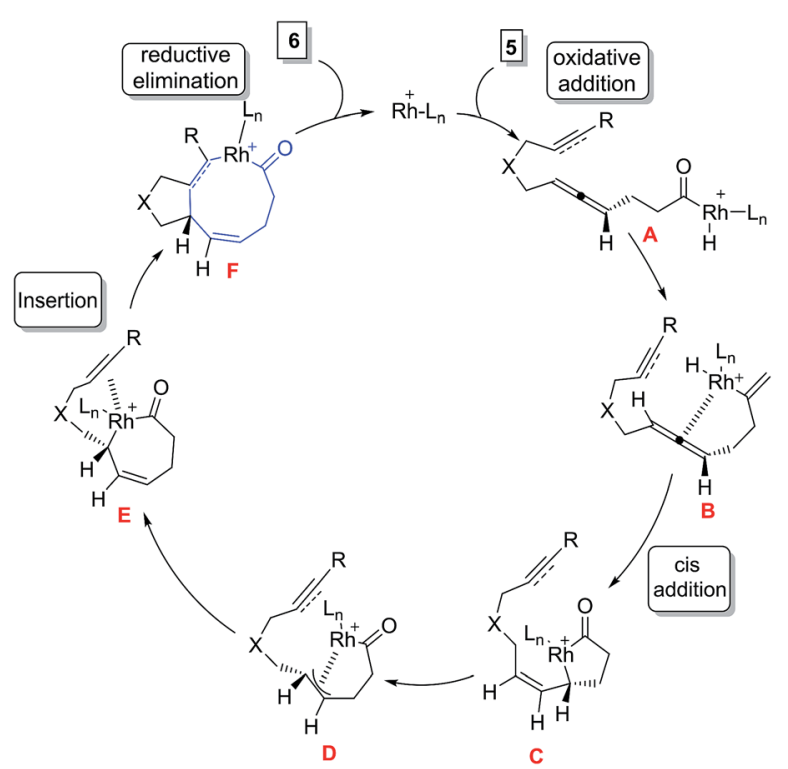

Fig. 3 Proposed mechanism for rhodium catalysed [6 + 2] cycloaddition reactions of allenals. 


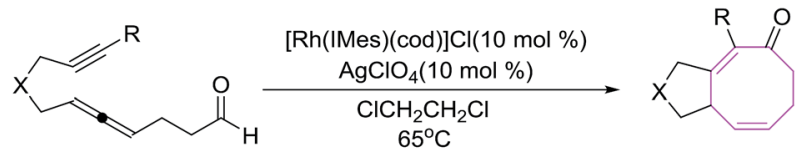

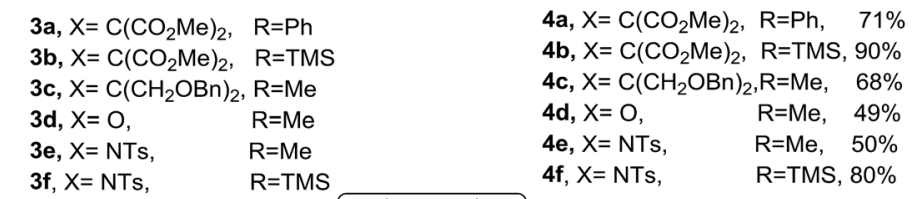
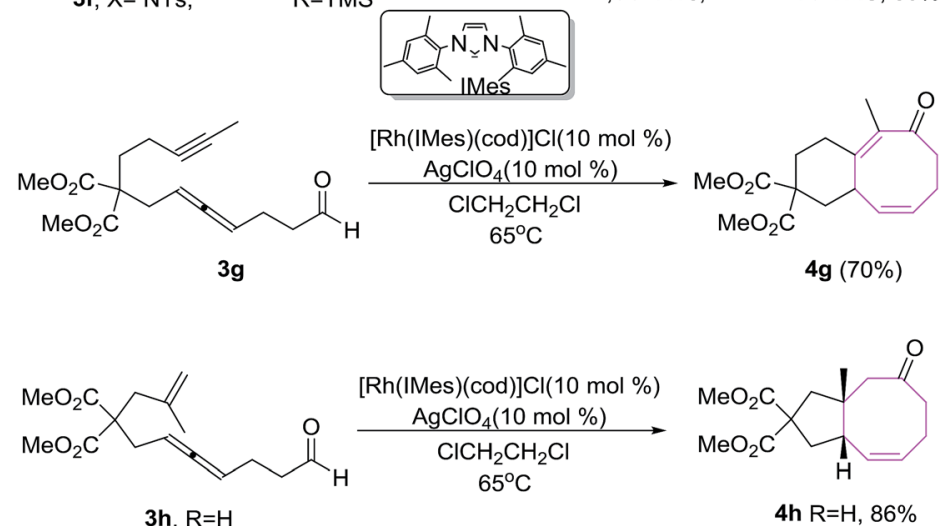

Scheme $2 \mathrm{Rh}(\mathrm{I})$-catalyzed [6 + 2] cycloaddition of alkene tethered allenal.

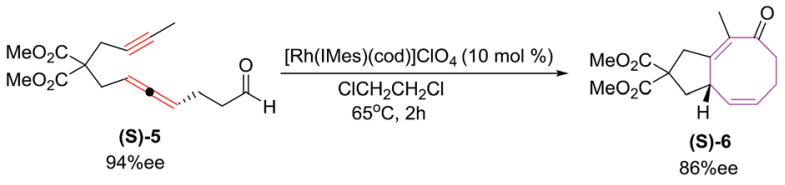

Scheme $3 \mathrm{Rh}(1)$-catalyzed [6 + 2] cycloaddition of alkyne tethered allenal.
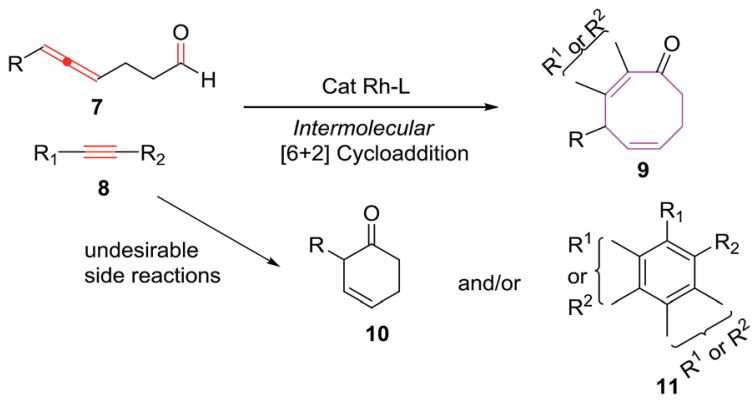

Scheme 4 Intermolecular [6 + 2] cycloadditions.

membered carbocycle 9 (61\%) and six-membered carbocycle 12 $(19 \%)$. Other tested catalysts such as $\left[\mathrm{RhCl}\left(\mathrm{PPh}_{3}\right)_{3}\right]$ and $[\mathrm{Rh}(\mathrm{dppe})] \mathrm{ClO}_{4}$ do not promote the intermolecular $[6+2]$ cycloaddition reactions (Scheme 5).

The intermolecular $[6+2]$ cycloadditions of $7 \mathbf{a}$ with various terminal alkynes possessing benzyloxy $\mathbf{8 b}-\mathbf{c}$, benzoate $\mathbf{8 d}$ and sulphonamide moiety $\mathbf{8 e}$ have also been reported to proceed in a stereoselective manner affording eight membered carbocycles $\mathbf{9 b - e}$ in high yields. The propargyl tethered alkyne moiety $\mathbf{8 f}$, however, provide regiomeric cyclooctadienone $9 f$ and $\mathbf{9} \mathbf{f}^{\prime}$ in yields of $64 \%$ and $10 \%$ respectively. Employing 1-hexyne have yielded a mixture of isomeric eight-membered rings $\mathbf{9 g} / \mathbf{9} \mathbf{g}^{\prime}$ in $68 \%$ and $5 \%$ yields along with six-membered carbocycles as side product $12 \mathrm{~g}$ (11\%). Electron-withdrawing carboxylate functionality on alkyne nucleus $\mathbf{8 h}$ have led to the regiomeric cyclooctadienones $\mathbf{9 h} / \mathbf{9} \mathbf{h}^{\prime}$ in comparatively lower yields (56\% \& $22 \%$ respectively). 4-Allenal substituted with benzyloxy $7 \mathbf{a}-\mathbf{b}$, benzyl 7c, sulphonamide $\mathbf{7 d}$ and TMS 7e afford regioselective octa cyclic compounds $9 a, \mathbf{i}-\mathbf{1}$ in yields of $69 \%, 81 \%, 72 \%$ and $82 \%$ respectively. Phenyl substitution on allene however, retards the reaction rate and regioselectivity resulting in isolation of $\mathbf{9 m} / \mathbf{9 m}$ in $51 \%$ and $23 \%$ respectively.

The allenal $\mathbf{7} \mathbf{g}-\mathbf{h}$ possessing alkyl substitution between allene and aldehyde have resulted in increased formation of hydroacylation product 12 -o in $28 \%$ and $17 \%$ yields along with intramolecular [6+2] cycloadducts 9 n-o in $37 \%$ and $44 \%$ yields respectively (Scheme 6).

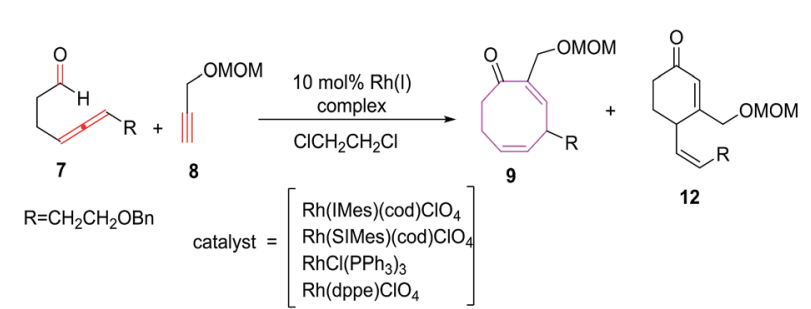

Scheme 5 Intermolecular [6 + 2] cycloadditions using various $\mathrm{Rh}(\mathrm{I})$ complexes. 

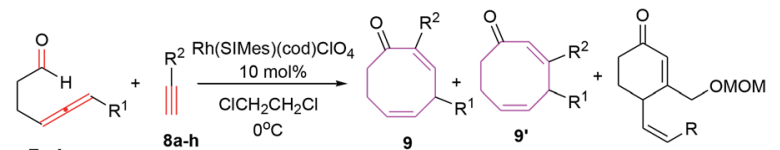

Entry $\quad \mathrm{R}^{1}$

9/9'/12 a: $\quad \mathrm{CH}_{2} \mathrm{CH}_{2} \mathrm{OBn}$,

9/9'/12 b: $\mathrm{CH}_{2} \mathrm{CH}_{2} \mathrm{OBn}$,

9/9'/12 c: $\mathrm{CH}_{2} \mathrm{CH}_{2} \mathrm{OBn}$,

9/9'/12 d: $\mathrm{CH}_{2} \mathrm{CH}_{2} \mathrm{OBn}$

9/9'12 e: $\quad \mathrm{CH}_{2} \mathrm{CH}_{2} \mathrm{OBn}$

9/9'/12 f: $\mathrm{CH}_{2} \mathrm{CH}_{2} \mathrm{OBn}$,

9/9'/12 g: $\mathrm{CH}_{2} \mathrm{CH}_{2} \mathrm{OBn}$,

9/9'/12 h: $\quad \mathrm{CH}_{2} \mathrm{CH}_{2} \mathrm{OBn}$

9/9'/12 i: $\quad \mathrm{CH}_{2} \mathrm{OBn}$,

9/9'/12 j: $\quad \mathrm{CH}_{2} \mathrm{CH}_{2} \mathrm{Ph}$,

9/9'/12 k: $\mathrm{CH}_{2} \mathrm{CH}_{2} \mathrm{NMeTs}$,

9/9'/12 I: TMS,

9/9'/12 m: $\mathrm{Ph}$

9/9'/12 o

$\begin{array}{cc}\mathbf{R}^{2} & \text { Yield(9/9'/12) } \\ \mathrm{CH}_{2} \mathrm{OMOM}, & 81 \% /-1 \text { - }\end{array}$

$\mathrm{CH}_{2} \mathrm{OBn}$,

74\% / - / -

$\mathrm{CH}_{2} \mathrm{CO}_{2} \mathrm{C}_{4} \mathrm{H}_{4}-\mathrm{Br}(\mathrm{p}), 75 \%$ / - /

61\% / -

$01 \% 1-r$

n-Bu, $\quad 68 \% / 5 \% / 11 \%$

$56 \% / 22 \% /-$

$\mathrm{CH}_{2} \mathrm{OMOM}$

$81 \% /-1$

- $\quad 82 \% /-1-$

$\begin{array}{ll}\mathrm{CH}_{2} \mathrm{OMOM}, & 82 \% /-1- \\ \mathrm{CH}_{2} \mathrm{OMOM}, & 51 \% / 23 \% / \text { - }\end{array}$

$\mathrm{CH}_{2} \mathrm{OMOM}$,

$37 \% /-128 \%$

$\mathrm{CH}_{2} \mathrm{OMOM}$,

$44 \% /-117 \%$

Scheme 6 Intermolecular [6 +2] cycloadditions of allenals and alkynes.

\section{$R h(I)$ catalysed $[6+2]$ cycloaddition reactions of allenylcyclobutanes}

Mukai et al. have devised a cycloisomerisation methodology using rhodium(I) catalysed alkyne-allenyl unfunctionalised cyclopropane/butane $\mathbf{1 3}$ to afford bicyclic and compounds $\mathbf{1 5}$ and 14 through $[5+2]^{21}$ and $[6+2]^{22}$ cycloaddition respectively. The un-functionalized simple cyclobutane ring in $[6+2]$ cycloadditions behaves as $6 \pi$-component and afford an easy construction of the bicyclo[6.3.0] undecatrienes 14 in good yields (Scheme 7).

The $[6+2]$ cycloaddition reactions are conceived by heating a solution of 13 in 1,2-dichloroethane at $80^{\circ} \mathrm{C}$ in the presence of $10 \mathrm{~mol} \%\left[\mathrm{RhCl}(\mathrm{CO})_{2}\right]$ as catalyst to afford the desired bicyclo [6.4.0]dodecatriene 14 in 40\% yield along with monocyclic side product $16(52 \%)$. Replacement of catalyst to $[\mathrm{RhCl}(\mathrm{CO}) \mathrm{dppp}]_{2}$ in toluene have witnessed a marked increase in yield of $6 / 8$ bicyclic product 14 (80\%). Other rhodium carbonyl catalysts are less effective in conceiving these $[6+2]$ cycloadditions. Best results for $[6+2]$ cycloaddition reactions are observed employing $\left[\mathrm{RhCl}(\mathrm{dppe})_{2}\right]$ as catalyst without carbon monoxide as ligand. A decrease in catalyst loading to $5 \mathrm{~mol} \%$ have observed a lowering in reaction yield of 14, however, using $5 \mathrm{~mol} \%$ $\left[\mathrm{RhCl}(\mathrm{dppe})_{2}\right]$ in $0.1 \mathrm{M}$ dioxane solvent at $80{ }^{\circ} \mathrm{C}$ have led to the formation of bicyclo[6.4.0]dodecatrienes 14 (87\%) (Scheme 8).

The proposed mechanism involves the coordination of $\mathbf{1 3}$ with $\mathrm{Rh}(\mathrm{I})$ complex through allenal double bond, $\mathrm{C}-\mathrm{C}$ bond of the strained cyclobutane ring and alkyne to produce intermediate $\mathbf{G}$, which opens up immediately to rhodabicyclo[4.3.0]
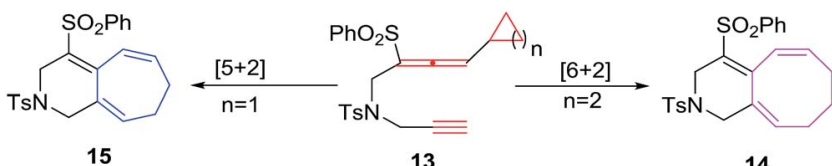

Scheme $7 \mathrm{Rh}(\mathrm{I})$ catalysed [6 +2$]$ reactions of unfunctionalised alkyneallenyl cyclopropane/butane.

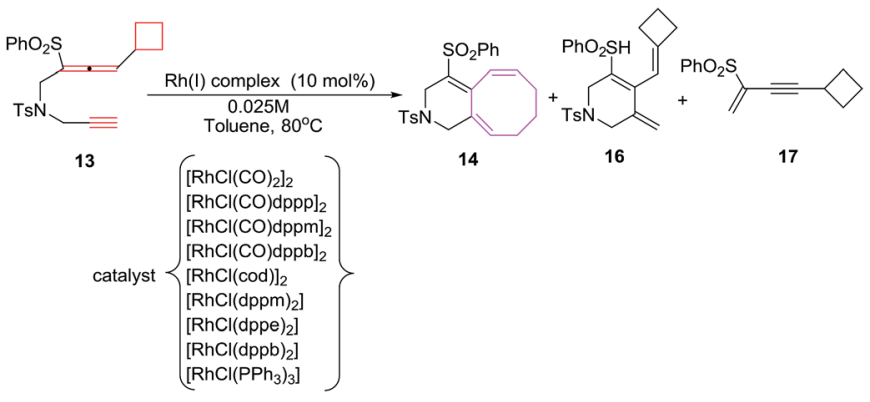

Scheme 8 Cycloadditions of alkyne-allenyl cyclobutane 13 in different $\mathrm{Rh}(1)$ complexes.

nonadiene intermediate $\mathbf{H}$ followed by $\pi$-carbon elimination of the strained cyclobutane ring of $\mathbf{H}$ leading to the formation of nine membered intermediate $\mathbf{I}$, which undergoes reductive elimination leading to bicyclo[6.4.0]dodecatrienes 14. However, $\pi$-hydride elimination instead of $\pi$-carbon elimination of $\mathbf{I}$ generates intermediate $\mathbf{J}$ which on reductive elimination yields monocyclic adduct 16. Alternatively, rhodacycle intermediate $\mathbf{K},{ }^{23-25}$ produced from ring opening of strained cyclobutane ring intermediate $\mathbf{G}$, undergoes insertion of $\mathrm{C}-\mathrm{Rh}^{\mathrm{III}}$ bond into the triple bond leading to the production of intermediate $\mathbf{I}^{22}$ (Fig. 4).

\section{$R h(I)$ catalysed [6 + 2] cycloadditions of cyclooctatrienes}

Conjugated cyclic trienes viz. cycloheptatrienes (CHT), cyclooctatrienes (COTT) etc. are excellent participants in $[6+2]$ cycloadditions as the embedded trienes in the favored cisoid confirmations acts as $6 \pi$ components with different alkenes, alkynes and dienes acting as $2 \pi$ component. The use of metal catalysts in these cycloaddition reactions have found an extensive place in literature. Metal catalysts such as titanium, ${ }^{26}$ ruthenium, ${ }^{27}$ molybdenum, ${ }^{28}$ cobalt $^{29}$ chromium $^{30}$ and iron ${ }^{31}$ complexes have been widely used to perceive such reactions.

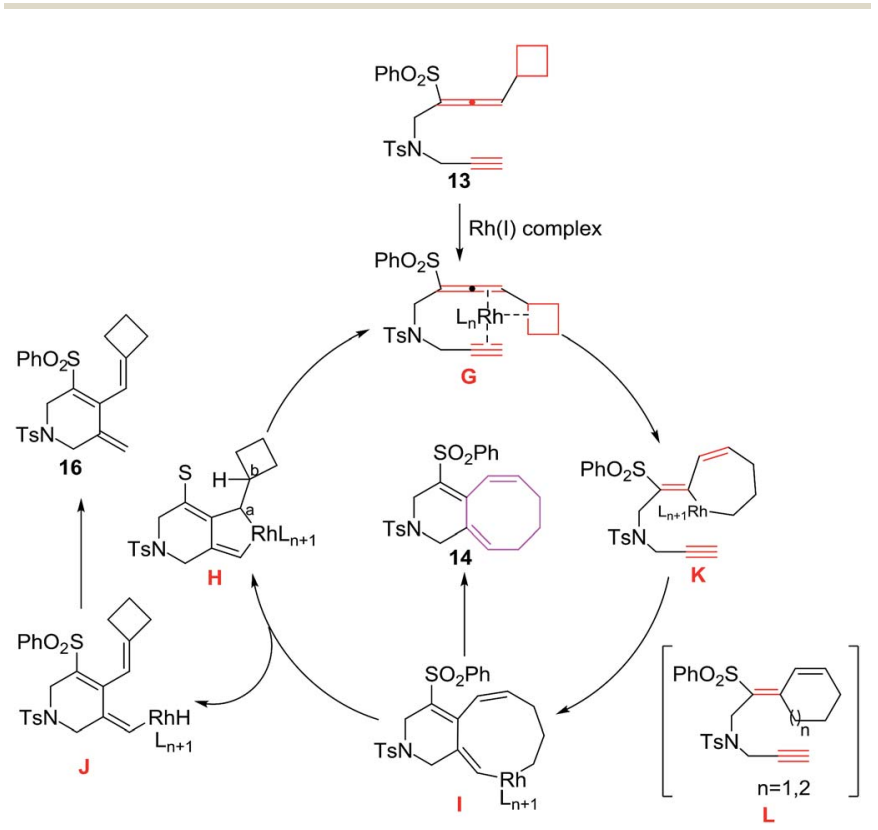

Fig. 4 Proposed mechanism for the formation of 14 
Mach et al. have engaged Ziegler catalyst $\left(\mathrm{TiCl}_{4} / \mathrm{Et}_{2} \mathrm{AlCl}\right)$ in achieving these $[6+2]$ cycloadditions. ${ }^{32}$ Rigby et al. have employed carbonylchromium(0) complex bearing labile ligand to effectively achieve $[6+2]$ cycloadditions. ${ }^{\mathbf{1 0 a}-\boldsymbol{d}}$ Buono et al. have recently established [6+2] cycloadditions of CHT with terminal alkynes. ${ }^{33}$ Also, cobalt(I) catalysed protocol has been applied to $[6+2]$ cycloadditions of COTT and internal and terminal akynes $^{34}$ and CHT to substituted allenes. ${ }^{35}$

Wang et al. have explored [6 +2$]$ cycloadditions of cycloheptatriene 18 with internal alkynes 19 employing different rho$\operatorname{dium}(\mathrm{I})$ catalysts. The $[6+2]$ cycloadditions do not occur using $\mathrm{PPh}_{3} \mathrm{RhCl}$ as catalyst at $60{ }^{\circ} \mathrm{C} .{ }^{36}$ The $[6+2]$ cycloadditions at elevated temperature $\left(120{ }^{\circ} \mathrm{C}\right)$ witness the formation of cycloadduct (64\%). Further increase in reaction temperature causes decrease in yield of 20 (53\%). Introducing additives such as CuI (10 mol\%) which acts as phosphine cleavage reagent ${ }^{37}$ have increased the yield of 20 (75\%). Exchanging the catalyst to $[\mathrm{Rh}(\mathrm{COD}) \mathrm{Cl}]_{2}$ steers the reaction to better results $(71 \%)$. Best results for $[6+2]$ cycloadditions $(88 \%)$ are witnessed using $[\mathrm{Rh}(\mathrm{COD}) \mathrm{Cl}]_{2}$ as catalyst along with $\mathrm{PPh}_{3}(10 \mathrm{~mol} \%)$ and $\mathrm{CuI}$ $(10 \mathrm{~mol} \%)$ at $120^{\circ} \mathrm{C}$. A number of terminal alkynes have been tried by Wang et al. The electron donating groups at para position of phenyl acetylene such as 19a, 19c, 19d and 19f have afforded better yields of $[6+2]$ cycloadducts $(88 \%, 85 \%, 87 \%$ and $88 \%$ respectively). Conversely, electron withdrawing substituents on alkyne such as $\mathbf{1 9} \mathbf{g}-\mathbf{h}, \mathbf{1 9} \mathbf{i}, \mathbf{1 9 j}, \mathbf{1 9 k}$ resulted in lowering of reaction yields to $70 \%, 73 \%, 70 \%, 72 \%$ and $67 \%$ respectively demonstrating the importance of electron donating substituents. No substitution on alkyne nucleus $19 \mathrm{~b}$ have led to $81 \%$ isolation of $20 \mathrm{~b}$. Introducing bulky groups as in 191-n have resulted in poor isolation of 201-n in $48 \%, 40 \%$ and $30 \%$ yields owing to the strong detrimental steric effect played by these groups (Scheme 9).

The mechanism for $[6+2]$ cycloadditions involves the initial conversion of catalytic precursor $\left[\mathrm{Rh}(\mathrm{COD}) \mathrm{Cl}_{2}\right]$ to $\left(\mathrm{Ph}_{3} \mathrm{P}\right)$ $\mathrm{Rh}(\mathrm{COD}) \mathrm{Cl} \mathbf{N}$, followed by exchange of COD ligand with CHT generating intermediate $\mathbf{O}$. Replacement of $\mathrm{PPh}_{3}$ with alkyne in the presence of $\mathrm{CuI}$ leads to intermediate $\mathbf{P}$ which immediately undergoes oxidative cyclometalation to intermediate Q. Addition of alkyne to $\mathbf{Q}$ produces $\sigma, \pi$-allyl complex $\mathbf{R}$ which undergoes reductive elimination through transition state $\mathbf{S}$ to

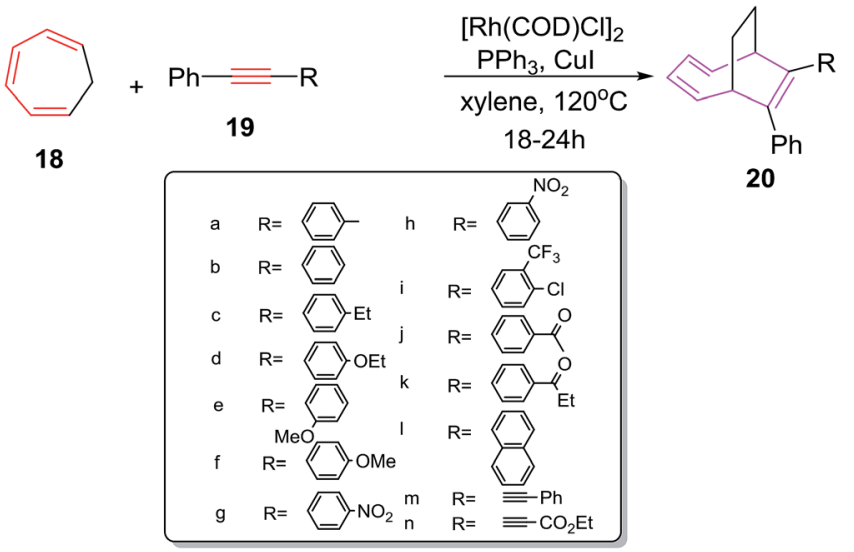

Scheme $9[6+2]$ cycloaddition of CHT with various alkynes.

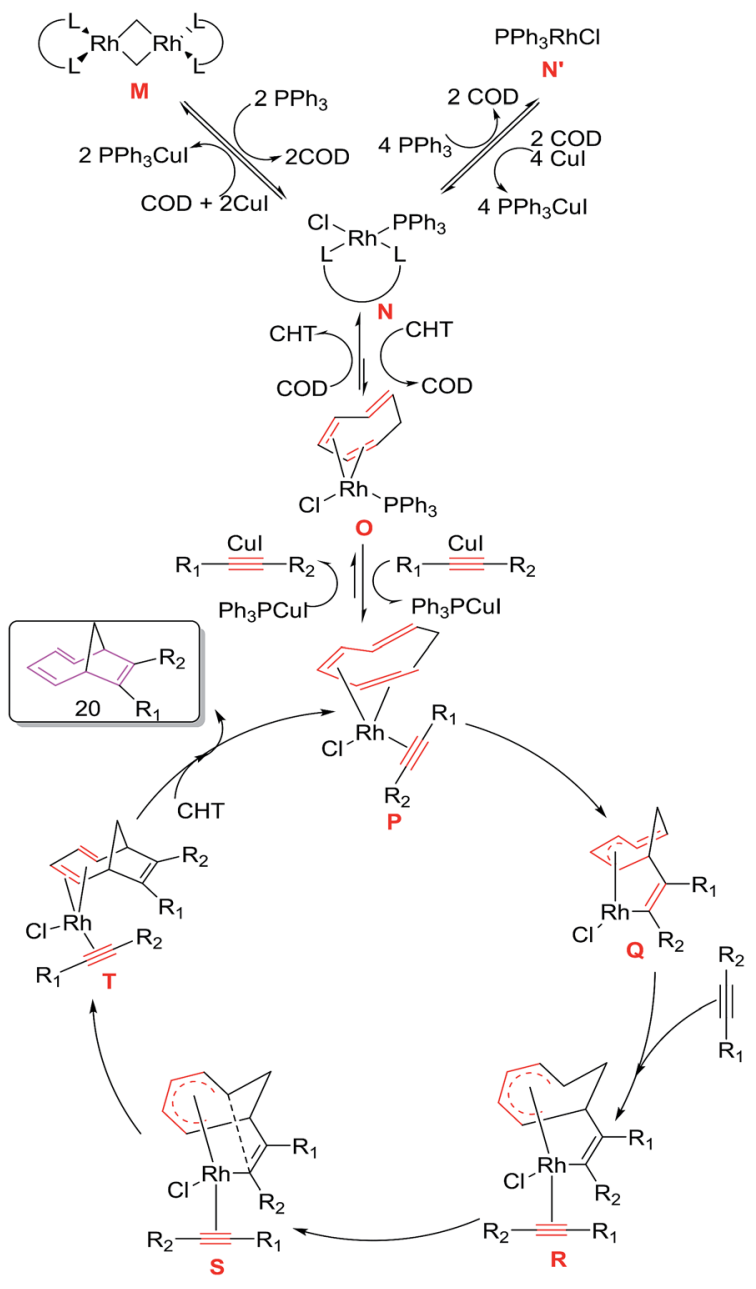

Fig. 5 Proposed Mechanism for rhodium catalysed [6 + 2] cycloaddition reaction of $\mathrm{CHT}$ with internal alkyne.

intermediate $\mathbf{T}$. Ligand exchange of $\mathbf{T}$ with $\mathbf{C H T}$ delivers cycloadduct $\mathbf{2 0}$ and regenerates rhodium complex $\mathbf{P}$ to renter the catalytic cycle. DFT calculations employing M06 function taking $\mathrm{Rh}(\mathrm{I})$ model as catalyst also confirms the proposed reaction mechanism with the observation of strong additive effect for the $\mathrm{CuI}$ in these $[6+2]$ reactions (Fig. 5).

\section{Cobalt catalyzed $[6+2]$ cycloadditions}

Co(I) complexes have been observed an excellent catalyst for [6+ 2] cycloadditions of cycloheptatrienes, cyclooctatetraenes, dicobalt acetylene complexes as $6 \mathrm{p}$-components with alkyne, allene enol silyl ethers as 2p-components to yield variety of monocyclic or condensed eight membered carbocycles. All the reported studies involve the intermolecular $[6+2]$ variants of these cycloadditions and $\mathrm{Co}(\mathrm{I})$ catalysed intramolecular $[6+2]$ cycloadditions are scarcely available in literature.

\section{[6 + 2] cycloadditions of cycloheptatriene (CHT) and alkynes}

Buono et al. have reported the first cobalt(I) catalyzed $[6+2]$ cycloadditions of cycloheptatriene (CHT) 18 with alkynes 21 to afford 7-alkyl-bicyclo[4.2.1] nona-2,4,7-trienes 22 (Scheme 10). ${ }^{38}$ Various cobalt(II) catalytic systems ${ }^{39}$ have been tested for $[6+2]$ 


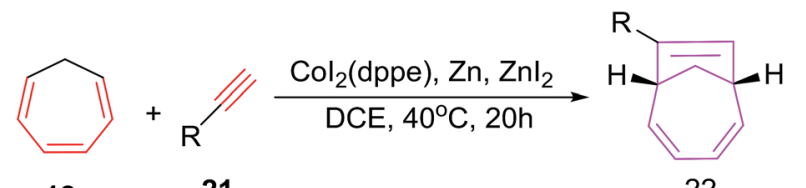

18 21

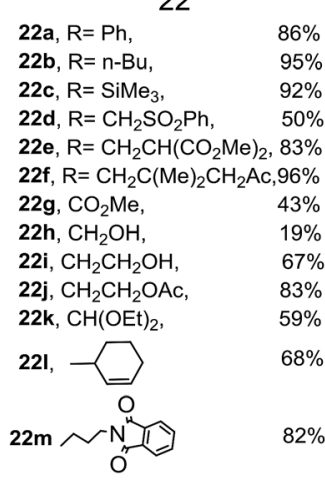

Scheme 10 Cobalt(॥) catalyzed [6 + 2] cycloaddition reactions of $\mathrm{CHT}$ with terminal alkynes.

cycloadditions. Best results are witnessed using cobalt(II)iodide/ 1,2-bis(diphenylphosphino)ethane (dppe) as catalyst, zinc metal as reducing agent, zinc iodide as a Lewis acid in $1: 3: 2$ molar ratio in 1,2-dichloroethane as solvent. The catalytic combination of $\mathrm{CoI}_{2}(\mathrm{dppe}) / \mathrm{Zn} / \mathrm{ZnI}_{2}$ have also proven excellent tolerance to various functional groups such as nitrile, alcohol, imide, sulfone, ketone, ester, ketal or ethers substituted alkyne 21a-m in their $[6+2]$ cycloaddition reactions with CHT 18. Alkynes having remotely substituted functional groups to the triple bond such as $\mathbf{2 1 f}, \mathbf{2 1 j}, \mathbf{2 1 m}$ afford cycloadducts $\mathbf{2 2 f}, \mathbf{2 2} \mathbf{j}$ and $22 \mathrm{~m}$ in excellent yields. The alkynes have substitution propargylic carbon 21d, 21k provide low yield of [6+2] cycloadducts. Electron poor alkynes such as methyl propiolate $\mathbf{2 1 g}$ have afforded [6+2] cycloadduct $22 \mathrm{~g}$ with poor yield $(21 \%)$ due to the preferential coordination of cobalt with $21 \mathrm{~g}$ initiating its cyclotrimerisation process. The efficacy of cobalt catalysed $[6+$ 2] cycloadditions are bettered using syringe pump controlled slow addition of the alkyne and lowering the catalyst loading (2.5 mol\%) (Scheme 10).

A plausible mechanism involves the $\mathrm{ZnI}_{2}$ reduction of $\mathrm{CoL}_{2} \mathrm{I}_{2}$ by zinc metal to cationic $\left[\mathrm{Co}(\mathrm{I}) \mathrm{L}_{2}\right]^{+}$complex which coordinates with alkyne 21 and CHT 18 followed by oxidative cyclometalation to produce cobalta-cyclopentene intermediate $\mathbf{U} .1,5-$ migration of the $\mathrm{C}\left(\mathrm{sp}^{3}\right)$-Co bond of $\mathbf{U}$ through consecutive $\sigma, \pi$ allyl complexes $\mathbf{V}$ and $\mathbf{W}$ leads to bicyclo cobalta-cycle $\mathbf{X}$ which on reductive elimination generates cycloadduct 22 and regenerates cationic intermediate $\left[\mathrm{Co}(\mathrm{I}) \mathrm{L}_{2}\right]^{+}$to return to the catalytic cycle $^{38}$ (Fig. 6).

An enantioselective version of the $[6+2]$ reactions has also been explored using phosphoramidite ligand as chirality inductors with improved yields and good enantioselectivity.

\section{[6 + 2] cycloadditions of cycloheptatriene (CHT) and allene}

Buono et al. have also reported cobalt catalyzed [6+2] cycloadditions of cycloheptatriene (CHT) 18 with variety of allenes $\mathbf{2 3}$ to afford bicyclic 7-bicyclo[4.2.1]nona-2,4-dienes 24 with an

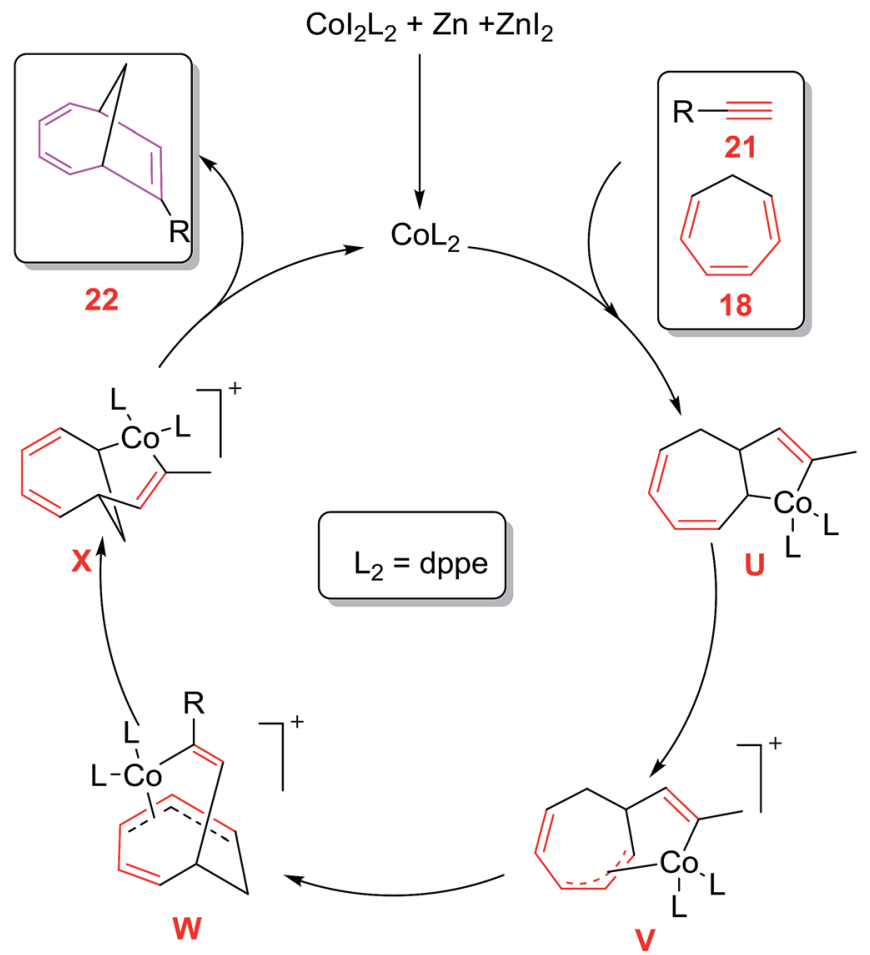

Fig. 6 Proposed Mechanism for cobalt catalysed [6 + 2] cycloadditions of CHT with terminal alkynes.

improved yield, enhanced regio- and geometrical selectivity (Scheme 11). The treatment of CHT 18 with phenylallene 23a under $\mathrm{CoI}_{2}$ (dppe)/Zn powder/ZnI $/ \mathrm{Zn}_{2}$ as catalytic system have resulted in an exclusive formation of $E$-isomer of 7benzylidenebicyclo[4.2.1]nona-2,4-diene 24a without the isolation of even traces of the other geometrical or regioisomer 25. Zinc metal plays a pivotal role in these cycloaddition reactions, absence of which leads to non-isolation of [6+2] cycloadduct. Also, ligand plays an equally important role as bis(diphenylphosphino)methane (dppm) and 1,3 bis(diphenylphosphino) propane (dppp) were ineffective in conceiving these reactions. Optimal reaction conditions leading to best results in terms of yield of 24 is witnessed using $\mathrm{CoI}_{2}$ (dppe) catalytic system with $\mathrm{Zn} / \mathrm{ZnI}_{2}$ reducing agent in 1,2-dichloroethane as solvent. ${ }^{40}$

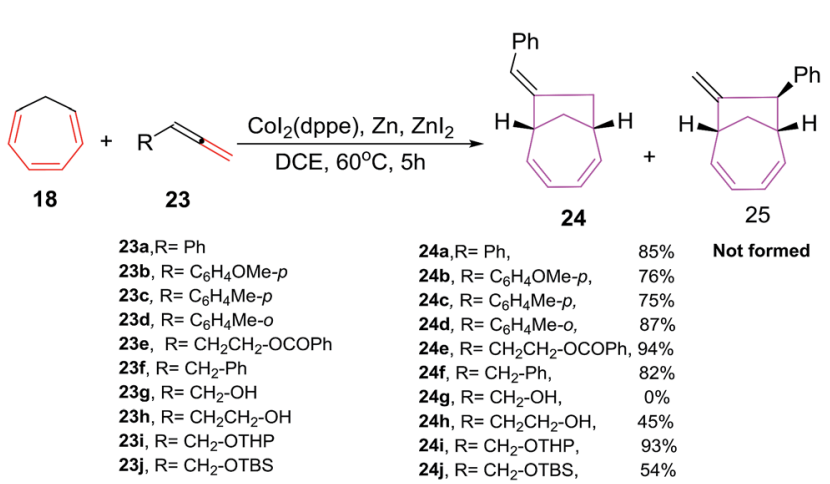

Scheme 11 Cobalt catalysed [6+2] reactions of CHT with substituted allenes. 
The $[6+2]$ cycloaddition reactions of monosubstituted allenes 23 are also studied using Co(II) complexed as catalysts. The methoxy or methyl substitution at ortho- or para- position of phenylallene 23a-d, is well accepted and lead to the exclusive formation of $E$-isomers $\mathbf{2 4 a - d}$ in good yields. [6+2] cycloadditions of benzylallene $23 \mathrm{f}$ with CHT 18 also leads to the exclusive formation of $E$-7-benzylidenebicyclo[4.2.1]nona-2,4-diene $24 \mathrm{f}$ in $82 \%$ yield. $\alpha$-allenol $\mathbf{2 3 g}$ and $\beta$-allenol $23 \mathrm{~h}$ are non reactive under these reaction conditions. With tetrahydropyranyl and benzoate protected $\alpha$-allenols $23 \mathbf{i}$ and 23e, excellent yields of 93\% and $94 \%$ are achieved for cycloadducts $24 \mathbf{i}$ and $24 \mathbf{e}$ respectively. Conversely, tert-butyl dimethylsilyl protected $\alpha$ allenols $23 \mathbf{j}$ leads to relatively low yields of $[6+2]$ cycloadducts $24 \mathbf{j}(54 \%)$ due to the degradation of allene during the catalytic cycle. The $[6+2]$ cycloadditions of disubstituted allenes, require high temperature and greater reaction time to manage similar results both in terms of yield and selectivity ${ }^{\mathbf{4 0}}$ (Scheme 11).

\section{$[6+2]$-cycloadditions of cyclooctatetraene and terminal allenes}

D'yakonov et al. have accomplished the Co(I) catalyzed [6 +2]cycloadditions of 1,3,5,7-cyclooctatetraene 26 (COTT) with functionalized terminal allenes $27 \mathbf{a}-\mathbf{e}$ in the presence of $\mathrm{CoI}_{2} /$ dppe/Zn/ZnI 2 catalytic system using 1,2-dichloroethane as solvent at $60{ }^{\circ} \mathrm{C}$ to afford (E)-bicyclo[4.2.2]deca-2,4,7-trienes 28a-e in good yields (78-85\%; Scheme 12). ${ }^{41}$ The reactions are gauged using varied reaction and catalytic system. It is observed that $\mathrm{CoI}_{2}$ or $\mathrm{ZnI}_{2}$ alone do not conceive the reactions even at elevated temperature $\left(100{ }^{\circ} \mathrm{C}\right)$.

The $[6+2]$ cycloadditions of COTT 26 with 1,2-cyclononadiene $27 \mathbf{f}$ under similar reaction conditions afford tricyclo [9.4.2.0]heptadeca-2,12,14,16-tetraene $28 f$ in 65\% yield. Interestingly, the reactions also proceed further to produce regioand strereomeric bis-adduct mixture 29a and 29b in total yield of $30 \%{ }^{41}$ (Scheme 13).

\section{[6 + 2] cycloadditions of cyclooctatetraene with alkynes}

Buono et al. have also explored the cobalt-catalyzed $[6+2]$ cycloadditions of cyclooctatetraene $\mathbf{2 6}$ with alkynes $\mathbf{3 0 a}-\mathbf{j}$ for the synthesis of monosubstituted bicyclo[4.2.2]-deca-2,4,7,9tetraenes 31a-j in fair to good yields (56-94\%). The reaction of phenylethyne 30a with COTT 26 using $\mathrm{CoI}_{2}$ (dppe) as catalyst/ ligand and $\mathrm{ZnI}_{2} / \mathrm{Zn}$ as Lewis acid/reducing agent couple in 1,2-

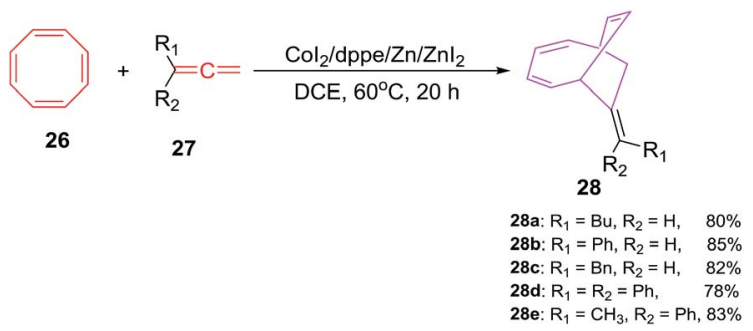

Scheme 12 Cobalt(॥) catalysed [6 + 2] cycloaddition reactions of COTT with terminal allenes.

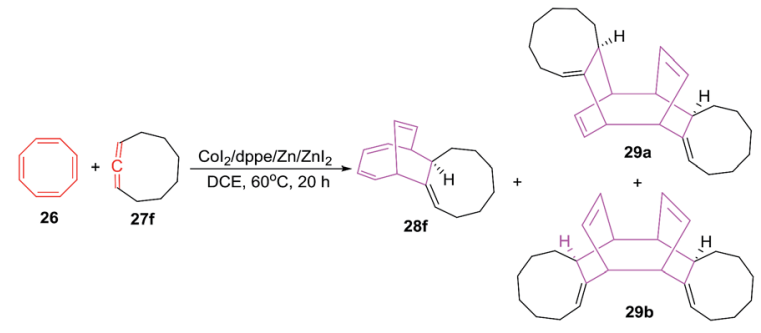

Scheme 13 Cobalt(II) catalysed [6 + 2] cycloaddition reactions of COTT with cyclic allene.

dichloroethane at $40{ }^{\circ} \mathrm{C}$ have resulted in the isolation of 7phenylbicyclo[4.2.2]deca-2,4,7,9-tetraene $\mathbf{3 1 a}$ in $70 \%$ yield. Alternatively employing $\mathrm{CoI}_{2}$ (dppe), $\mathrm{Bu}_{4} \mathrm{NBH}_{4} / \mathrm{ZnI}_{2}$ catalytic system have led to the isolation of $31 \mathrm{a}$ in $66 \%$ yield. The reaction protocol had proven to be of wide spread applicability as various functionalities on alkyne nucleus viz. ester, amide, nitrile, sulphonate, ketone, sulphones and trimethylsilyl are very well accepted as evident from moderate to good yields of [6 +2 ] cycloadducts 31a-j (56-94\%; Scheme 14). ${ }^{42}$

The $[6+2]$ cycloadditions encountered similar success when COTT 26 is made to react with symmetrical alkynes 30k-1 for synthesis of cycloadducts $31 \mathbf{k}-\mathbf{l}$ in yields of $78 \%$ and $77 \%$ respectively. The $[6+2]$ cycloadditions however have failed for diphenylethyne or 3-hexyne (Scheme 15). ${ }^{42}$

The cobalt-catalyzed cycloadditions of cyclooctatrienes (COT) 32 with various alkynes 30a-e afford a mixture of desired $[6+2]$ cycloadducts $33 \mathbf{a}-\mathbf{e}$ and tricyclic adduct $34 \mathbf{a}-\mathbf{e}$. The absence of cycloadducts of type 35 and 36 from the product range rules out the possible $[4+2]$ cycloaddition pathway for COTT 26 and COT 32 (Scheme 16).

The COT 32/COTT 26 can exist in two isomeric forms namely monocyclic form $\mathbf{X}$ and $6 \pi$ bicyclic isomeric electrocycle $\mathbf{Y}$. The $[6+2]$ cycloaddition of terminal alkyne $\mathbf{3 0}$ to isomeric form $\mathbf{X}$ have resulted in the formation of desired cycloadduct $\mathbf{3 3}$, whereas, $[4+2]$ cycloaddition of $\mathbf{3 0}$ to bicyclic isomeric form $\mathbf{Y}$ have led to the isolation of cycloadduct 34. The direct non participation of $\mathbf{X}$ in $[4+2]$ cycloaddition with terminal alkyne 30 have resulted in non isolation of hypothetical products 35 and 36 (Fig. 7).

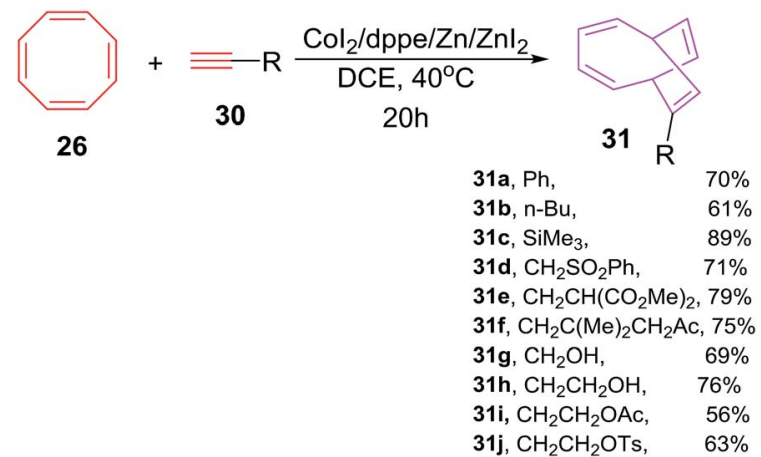

Scheme 14 Cobalt-catalyzed [6 + 2] cycloadditions of cyclooctatetraene with terminal alkynes. 
<smiles>C1=CC=CC=CC=C1</smiles>

26

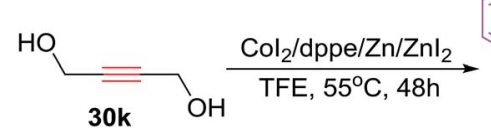

$30 k$

$\mathrm{OH}$

, $55^{\circ} \mathrm{C}, 48 \mathrm{~h}$

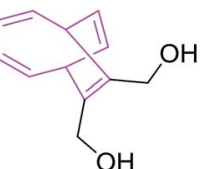

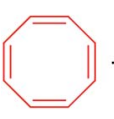

26
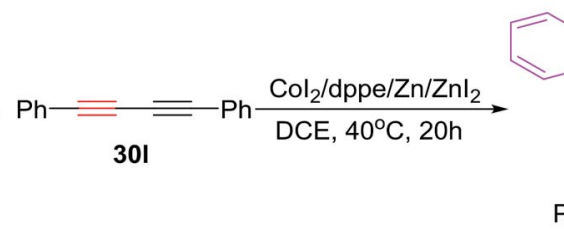

31

Scheme 15 Cobalt-catalyzed [6 + 2] cycloadditions of cyclooctatetraene with symmetrical alkynes.

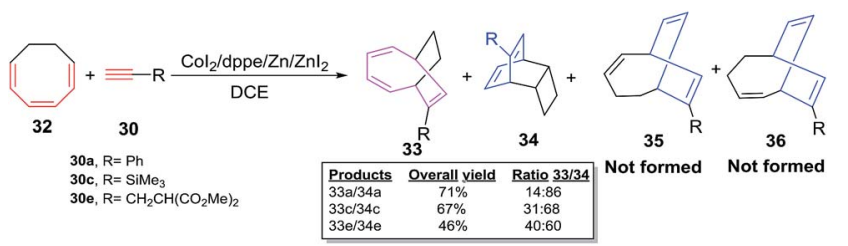

Scheme 16 Cobalt-catalyzed [6 + 2] cycloadditions of cyclooctatriene (COT) with terminal alkynes.

Mechanistically, the reaction is expected to proceed through two pathways. Oxidative cyclometallation of $\mathbf{I}$ followed by its coordination to alkyne $\mathbf{3 0}$ generates cobaltacycle VI in the first path. Alkyne insertion to Co-C bond leads to cobaltabicycle $\mathbf{V}$, which on reductive elimination of cobalt affords cycloadduct $31 / 33$ and regenerates active $\left[\mathrm{CoL}_{2}\right]^{+}$to renter the catalytic cycle. In the second path, oxidative cyclometallation of II leads to complex III which on 1,3-migration of $\mathrm{Co}-\mathrm{C}\left(\mathrm{sp}^{3}\right)$ bond through $\sigma-\pi$-allyl complex forms cobaltabicycle adduct $\mathbf{V}$. Formation of $[4+2]$ cycloadduct proceeds via sequential oxidative cyclometallation, alkyne insertion and reductive elimination of intermediate VII and VIII leading to product 34 (Fig. 8). ${ }^{\mathbf{4 2}}$

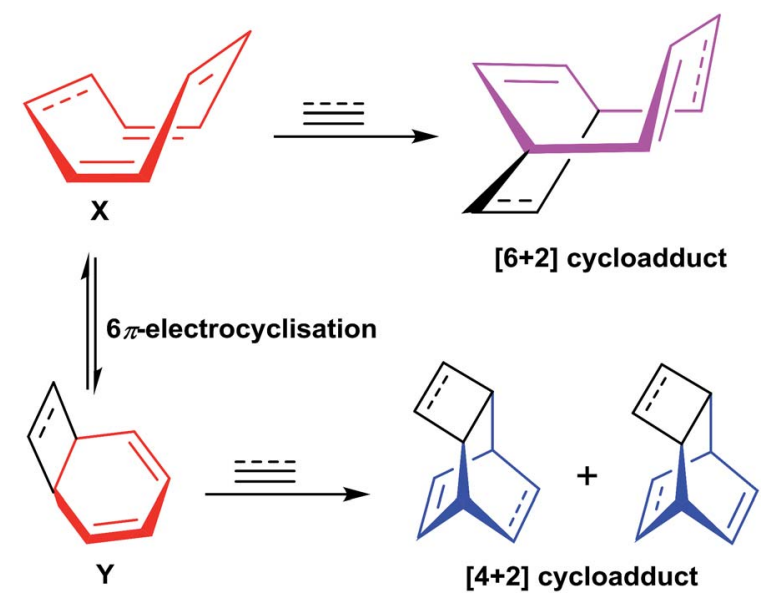

Fig. 7 Valance tautomeric forms of COT/COTT and their participation in cycloadditions with alkynes.
$[6+2]$ cycloadditions of dicobalt acetylene complex with enol silyl ethers

Tanino et al. have developed methodology for the stereoselective synthesis of cyclooctanones $\mathbf{4 0}$ by formal $[6+2]$ cycloadditions of a hexa carbonyl dicobalt acetylene complex $\mathbf{3 8}$ ( $6 \pi$ component) with several enol silyl ethers $2 \pi$ component 37 under the influence of $\mathrm{EtAlCl}_{2}$.

The methodology holds special importance as no side product arising from intramolecular cyclisation/homo coupling of the cobalt complex is noticed which allowed equivalent mixing of reactants without employing high dilution synthesis (Scheme 17). ${ }^{43}$

The reaction proceeds with the stereoselective formation of dicobalt acetylene complex 39 in good yields. Acyclic enol silyl ethers 37c, 37d, 37e produce cycloadducts 39c, 39d and 39e in $73 \%$ (88:12), 68\% (cis) and 83\% (86:14) yields respectively with the major product having cis arrangement of alkyl and silyloxy group. However, trans fused cyclooctanone $39 \mathrm{f}$ is obtained as a single cycloadduct ( $81 \%$ ) by employing cyclic enol silyl ether $\mathbf{3 7 f ^ { 4 3 , 4 4 }}$

The $[6+2]$ cycloadditions can be utilized to generate a model compound of taxane diterpenoid. The B-C ring system of taxane is constructed by employing $[6+2]$ cycloaddition reaction of diacetylene dicobalt complex 38 with cyclic enol silyl ether $\mathbf{3 7 f}$. $^{\mathbf{4 5}}$

\section{Titanium(II) catalyzed [6 + 2] cycloadditions}

Titanium complexes has successfully tested in [6+2] cycloadditions of variety of cycloheptatrienes, cyclooctatetraenes,

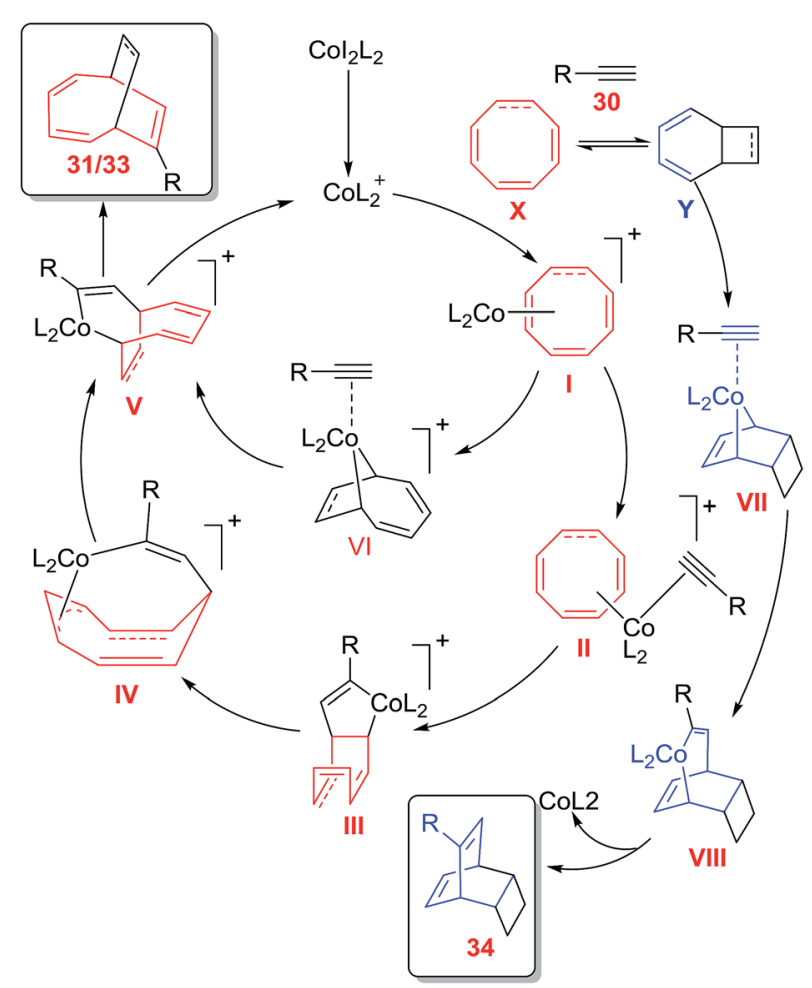

Fig. 8 Proposed mechanism for cobalt catalysed cycloadditions of COTT 26/COT 32 with terminal alkynes 30 


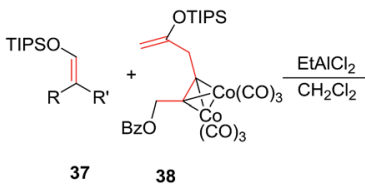

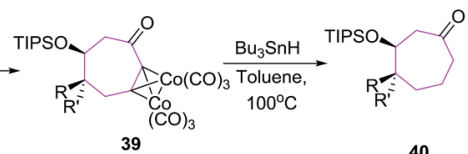
$37 \quad 38$

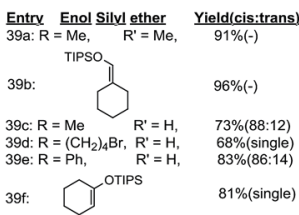

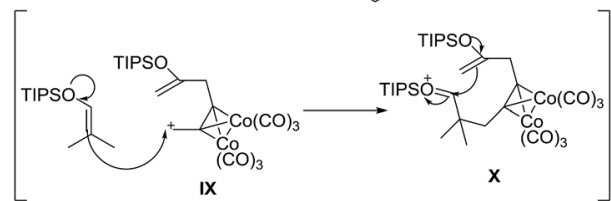

Scheme 17 [6 + 2] cycloadditions of various enol silyl ether with dicobalt acetylene complex.

bis(1,3,5-cycloheptatriene-7-yl)lkanes as $6 \pi$-components with alkyne, 1,2-dienes, as $2 \pi$-components to yield variety of monocyclic or condensed eight membered carbocycles. All the reported studies involve only intermolecular variants of $[6+2]$ cycloadditions.

Titanium(II) catalyzed [6 + 2] cycloadditions of cycloheptatrienes with alkynes

D'yakonov et al. have explored the [6+2] cycloadditions of 7alkyl(allyl,phenyl)-1,3,5-cycloheptatrienes 41 with alkynes 42 catalyzed by the two-component $\mathrm{Ti}(\mathrm{acac})_{2} \mathrm{Cl}_{2}-\mathrm{Et}_{2} \mathrm{AlCl}$ system, resulting in the formation of substituted bicyclo[4.2.1]-nona2,4,7-trienes $\mathbf{4 3} / 44$ in excellent yields (up to 90\%). The addition of alkyne 42 to the cycloheptatriene 41 (1:1) occurs in a stereoselective manner to afford predominantly syn-isomer. The [6 + 2] cycloadditions using alkyne $\mathbf{4 2}$ having ethyl-, butyl-, phenyl-, and allyl-substituted cycloheptatrienes 41b, 41c, 41d and 41e lead to cycloadducts 43c-j syn-specificity (Scheme 18). ${ }^{\mathbf{4 6}}$

Symmetrical alkynes such as hex-3-yne, oct-4-yne and dec-5yne are incompetent $2 \pi$ components in [6+2] cycloadditions and have shown competitive homo-cyclotrimerization. The $[6+$ 2] reactions afford bicyclic systems $\mathbf{4 3} / \mathbf{4 4}$ using (i-PrO) ${ }_{2} \mathrm{TiCl}_{2}$

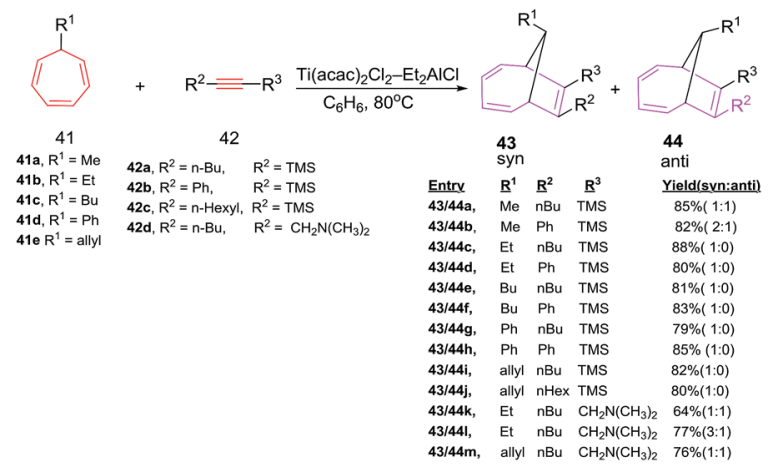

Scheme 18 Ti-catalyzed [6 + 2] cycloadditions of alkynes to 7substituted 1,3,5-cycloheptatrienes. and $(t-\mathrm{BuO})_{2} \mathrm{TiCl}_{2}$ or $\mathrm{TiCl}_{4}$ as catalysts. ${ }^{46}$ The $[6+2]$ reactions of 7-alkyl(allyl,phenyl)-1,3,5-cycloheptatrienes 41 with Sicontaining alkynes 45 catalyzed by the $\mathrm{Ti}(\mathrm{acac})_{2} \mathrm{Cl}_{2} / \mathrm{Et}_{2} \mathrm{AlCl}$ system, furnish substituted bicyclo[4.2.1]nona-2,4,7-trienes 46 in good yields (79-88\%; Scheme 19).

\section{[6 + 2] cycloadditions of cycloheptatrienes with 1,2-dienes}

D'yakonov et al. have also envisaged [6+2] cycloadditions of functionalized cycloheptatrienes $\mathbf{4 1}$ with allenes(1,2-dienes) 27 using $\mathrm{Ti}(\mathrm{acac})_{2} \mathrm{Cl}_{2}-\mathrm{Et}_{2} \mathrm{AlCl}$ system as catalyst to generate predominantly endobicyclo[4.2.1]-nona-2,4-dienes 47a-f in good yields. ${ }^{47}$ The enhanced syn selectivity is largely attributed to the steric bulk at 7-position of CHT nucleus (Scheme 20).

D'yakonov et al. have also studied [6+2] cycloadditions reactions using functionalized cycloheptatrienes $\mathbf{4 1}$ and 1,2 cyclononadiene $27 \mathbf{f}$ to yield a mixture of syn and anti of isomeric tricycle[9.4.1.0]-hexadeca-2,12,14-trienes $\quad$ 48a-d $\quad$ (78-85\%; Scheme 21). ${ }^{47}$

\section{$[6+2]$ cycloadditions of bis(1,3,5-cycloheptatriene-7-yl)lkanes 47 and alkynes}

D'yakonov et al. have explored [6 + 2] cycloadditions of Sicontaining alkynes $\mathbf{4 5}$ and bis(1,3,5-cycloheptatriene-7-yl) alkanes 49 using $\mathrm{Ti}(\mathrm{acac})_{2} \mathrm{Cl}_{2}-\mathrm{Et}_{2} \mathrm{AlCl}$ as catalytic system, leading to selective formation of mono- and bis-adducts [9-[4(2,4,6-cycloheptatrienyl)alkyl]-8-alkyl(phenyl)bicyclo[4.2.1]nona2,4,7-triene-7-yl](trimethyl)silanes 50a-f and bis(7-trimethylsilyl8-alkyl(phenyl)bicyclo[4.2.1]nona-2,4,7-triene-7-yl)alkanes 51a-f in $78-88 \%$ yields respectively. The cycloaddition reactions of alkynes 45 and bis(1,3,5-cycloheptatriene-7-yl)alkanes 49 are stereoselective, resulting in the isolation of $s y n$-isomer. The high

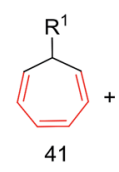

41a, $R^{1}=\mathrm{Me}$

41b, $R^{1}=E t$

41c, $R^{1}=\mathrm{Bu}$

41d, $R^{1}=P h$

41e $\mathrm{R}^{1}=$ allyl

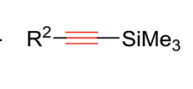

45

$45 a, R^{1}=n \_B u$

$45 b, R^{1}=P h$

45c, $R^{1}=$ Hexyl
Scheme 19 Ti-catalyzed [6 +2] cycloadditions of silicon containing alkynes to 7-substituted 1,3,5-cycloheptatrienes (CHT).

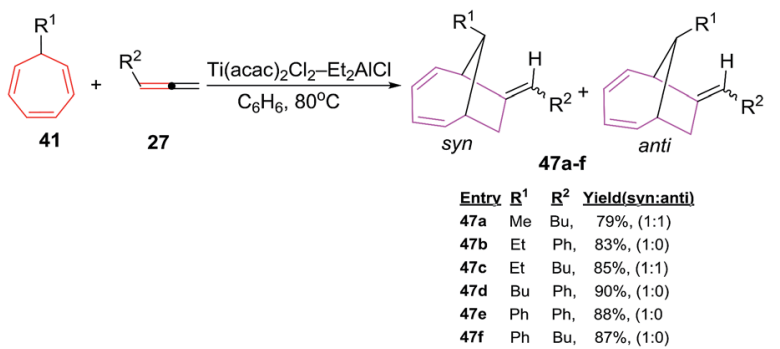

Scheme 20 Ti-catalyzed [6 + 2] cycloadditions of 1,2-dienes to 7substituted 1,3,5-cycloheptatrienes (CHT). 

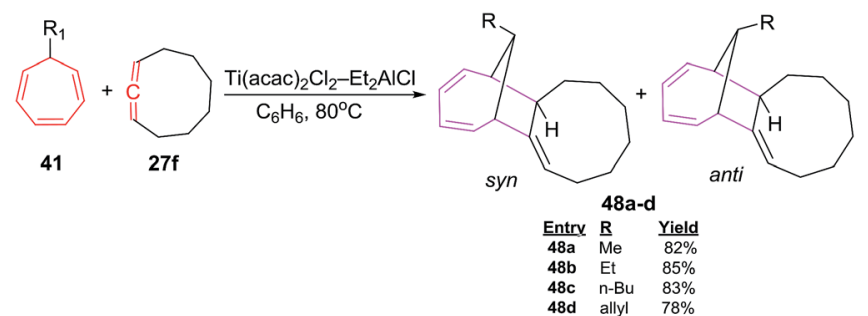

Scheme 21 Ti-catalyzed [ $6+2]$ cycloadditions of 1,2 cyclononadiene 7-substituted 1,3,5-cycloheptatrienes (CHT).

stereoselectivity is presumably attributable to steric factors associated with the bulky substituent at the bridging carbon atom in the initial bis(1,3,5-cycloheptatriene-7-yl)alkane $\mathbf{4 9}^{\mathbf{4 8}}$ (Scheme 22).

\section{Platinum(II) catalyzed intramolecular [6 + 2] cycloadditions}

Platinum(II) complexes has efficiently been explored in relatively less explored intramolecular variant of $[6+2]$ cycloadditions to afford bicyclic cyclopentane fused bicyclo[4.2.1]nona-2,4,7trienes. Tenaglia et al. have developed a facile, chemoselective and high yielding platinum-catalyzed (5 mol\%) en route for intramolecular $[6+2]$ cycloadditions of alkynes tethered to cycloheptatrienes $\mathbf{5 2 a - k}$ at room-temperature to afford cyclopentane fused bicyclo[4.2.1]nona-2,4,7-trienes 53a-k in good yields (66-99\%). The cycloisomerizations of 52 with other metal complexes such as $\left[\left\{\mathrm{RuCl}_{2}(\mathrm{CO})_{3}\right\}_{2}\right]$ and $\mathrm{AuCl}_{3}$ provide satisfactory results, whereas rhodium complexes are poor in catalysing these reactions. The best results are observed using $\mathrm{PtCl}_{2}$ ( $5 \mathrm{~mol} \%$ ) as catalysts. The reactions are also analyzed in different solvents, such as THF (85\%), acetone (91\%), toluene (94\%) are observed most promising solvent and cycloadditions in methanol, acetonitrile and DMF are unsuccessful. The $[6+2]$ cycloaddition can tolerate variety of substitutions at

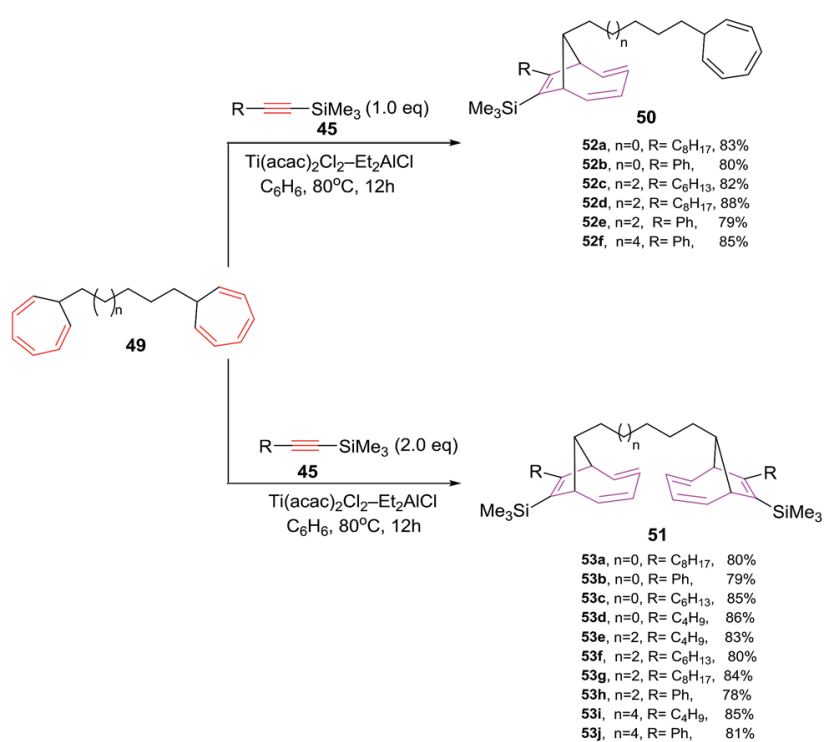

Scheme 22 Ti-catalyzed [6 +2] cycloadditions of silicon containing alkynes with bis-1,3,5-cycloheptatrienes (CHT). cycloheptatrienes such as CHT carrying acetal 52f, ether 52d-e, ester $\mathbf{5 2 h} \mathbf{h} \mathbf{j}$, sulfonate $\mathbf{5 2 b}$, cyclic carbonate $\mathbf{5 2 g}$, halide $\mathbf{5 2 k}$ or nitrile substituents 52c afford [6+2] cycloadducts in good yields. However, lengthening the tether by an additional carbon unit in $\mathbf{5 2}$ has a detrimental effect and no [6+2] cycloadduct is realised $^{49}$ (Scheme 23).

The CHT bearing internal alkynes 54a-e have been observed reluctant participants in intramolecular $[6+2]$ cycloadditions even at elevated reaction temperature $\left(110{ }^{\circ} \mathrm{C}\right.$; Scheme 24$)$.

Alkyl 54a-b and phenyl 54c substituted trienynes are unreactive whereas, electron deficient 54d-e afford $[6+2]$ adducts 55d-e albeit in low yields of $64 \%$ and $22 \%$ respectively. ${ }^{49}$

The intramolecular $[6+2]$ cycloisomerisations of trienynes $\mathbf{5 7} \mathbf{a}-\mathbf{g}$ bearing heteroatom in the tether yield $[6+2]$ cycloadducts 58 along with the formation of side products such as dihydropyranes or tetrahydropyranes $\mathbf{5 9}$ via 1,2-hydrogen or alkyl migration, along with other products 60, 61 and 62 as depicted in Scheme 25. ${ }^{49}$

The proposed mechanism involves the exo cyclisations of $\mathbf{5 7}$ leading to pentadienyl cationic intermediate IX which through electronic redistribution affords $[6+2]$ cycloadducts 58 . With trienyne bearing an acyl functionality, carbonyl group trigger the cyclisation of 57, leading to dihydropyran 59. Endocyclisation of $\mathbf{5 7}$ through zwitter ion $\mathbf{X}$ and platinacarbene intermediate XI leads to product $\mathbf{5 9}$ presumably through a 1,2hydrogen/alkyl shift followed by the elimination of metal ion. Formation of 60 is owed to the coordination of $\mathrm{Pt}^{2+}$ species to distant double bond of $\mathbf{5 9}$ followed by ring cleavage of the cyclopropane moiety. The tetrahydropyran ring opening of 58c/ 58e driven by $\mathrm{HCl}$ (generated from $\mathrm{PtCl}_{2}$ ) affords tertiary allylic carbocation yielding products 61 and 62 respectively ${ }^{49}$ (Fig. 9).

\section{Ruthenium( $(0)$ catalyzed $[6+2]$ cycloadditions of cyclooctatriene (COT) with alkenes}

Mitsudo et al. have envisaged [6+2]cycloaddition reactions of ruthenium(0) complex such as $\operatorname{Ru}\left(\eta^{4}-\operatorname{cod}\right)\left(\eta^{6}-\cot \right) 63$ with

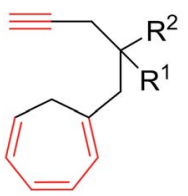

52
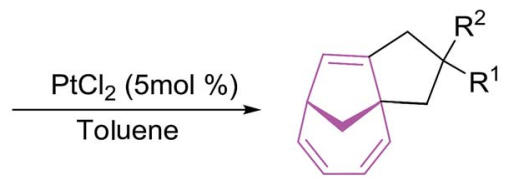

53
Scheme $23 \quad \mathrm{PtCl}_{2}$-catalyzed [6 + 2] cycloadditions of alkynes tethered to cycloheptatrienes 54 . 


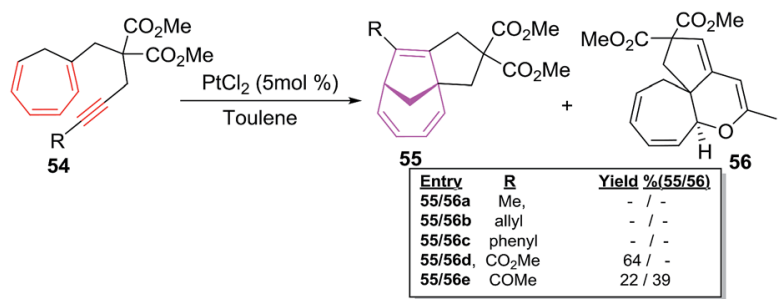

Scheme $24 \mathrm{PtCl}_{2}$-catalyzed [6 +2] cycloadditions of trienynes $54 a-e$.

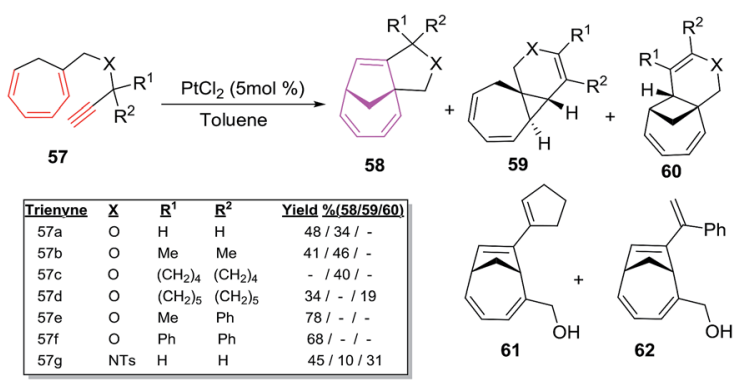

Scheme $25 \mathrm{PtCl}_{2}$-catalyzed [6 + 2] cycloadditions of heteroatom tethered trienynes $57 \mathrm{a}-\mathrm{g}$.

maleic anhydride $64 \mathrm{a}$ or maleimides $64 \mathrm{~b}-\mathbf{e}$ to generate a series of novel divalent ruthenacycles $65 \mathbf{a}-\mathbf{e}$. The reaction proceeds by employing equivalent amounts of both reactants in $n$-hexane as solvent for $2 \mathrm{~h}$ to afford ruthenacycles $\mathbf{6 5 a}-\mathbf{e}^{50}$ (Scheme 26).

Mitsudo et al. have also studied electron deficient alkenes such as dimethyl fumarate and dimethyl maleate in $[6+2]$ cycloadditions to afford $\operatorname{Ru}\left(\eta^{5}-\cot \right)\left(\eta^{2}\right.$-dimethyl fumarate $){ }^{51}$ Employing $p$-benzoquinone in place of maleic anhydride produces an uncharacterizable mixture of products. $\mathrm{N}, \mathrm{N}$ Dimethylacrylamide and methyl vinyl ketone are ineffective in conceiving these reactions. Terminal alkynes on the other hand have afforded a zerovalent $\eta^{4}, \eta^{2}$-bicyclodecatriene product. ${ }^{52}$ The proposed mechanism for the production of ruthenacycles 65 involves the change of coordination mode of COT ligand of 63 from $1-6-\eta^{6}$ to $1-2: 5-6-\eta^{4}$ or $1-4-\eta^{4}$ followed by 64 occupying

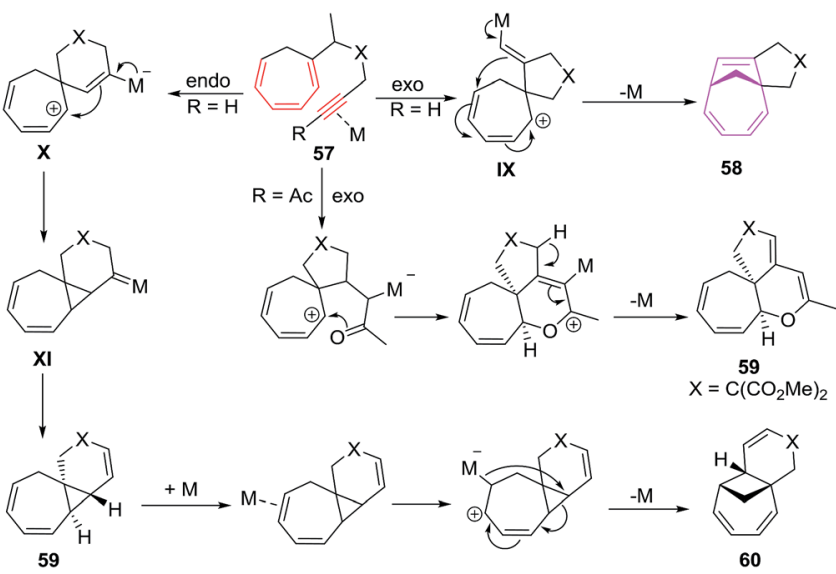

Fig. 9 Proposed mechanism for cycloisomerisations of trienynes. its vacant coordination site to either produce intermediate XIIa or XIIIa. The oxidative cyclisation of COT and 64 generates ruthenacycles intermediates XIIb and XIIIb, which recoordinates of the $\mathrm{C}=\mathrm{C}$ bond affording desired ruthenacycles 65 (Fig. 10). ${ }^{50}$

The ruthenacycles $65 \mathbf{a}-\mathbf{e}$ react in a number of ways to create cyclooctyl complexes 66-70 respectively. The ruthenacycles 65d, for example, on hydrogenation at 1 atm pressure affords $N$ phenylcyclooctylsucciniimide 66 in overall yields of $56 \%$. The treatment of 65d with $\mathrm{HCl}$ in $\mathrm{Et}_{2} \mathrm{O}$, however, have resulted in the formation of $N$-phenyl(3,5-cyclooctadien-1-yl)succiniimide 67 in $62 \%$ yield using mild reaction conditions. The ruthenacycle $65 \mathbf{d}$ undergoes ring closure via reductive elimination at high temperature to afford tricyclic $[6+2]$ cycloadduct 68 . Introduction additives such as $\mathrm{PPh}_{3}$ promotes the production of 68 from 65d, while 1,2-bis(diphenylphosphino)ethane (dppe) does not yield 68, instead stable ruthenacycle 69 is formed $(71 \%)$ presumably via ligand displacement between COD and dppe. The reaction of $65 \mathbf{d}$ with $\mathrm{CO}$ in toluene at $1 \mathrm{~atm}$ pressure for $3 \mathrm{~h}$ have resulted in the isolation of ticarbonyl ruthenacycle complex 70 in an overall yield of $76 \%$. The reaction proceeds with full dissociation of COD ligand from $\mathbf{6 5 d}$ followed with the insertion of three molecules of CO coordinated to Ru along with cycloheptadienyl hapicity change from the change $\eta^{5}$ to $\eta^{3}$. The theoretical studies have also been carried to support the experimental results (Scheme 27). ${ }^{50}$

\section{$\mathrm{Cu}($ II) catalysed $[6+2]$ cycloaddition reactions}

Dethe et al. have recently studied highly regio- and diastereoselective facile, one pot Lewis acid catalysed [6 +2] cycloaddition reactions for the synthesis of highly substituted pyrrolo $[1,2-a]$ indoles having three contiguous stereocenters. The reactions of indole alcohol 71a-d with conjugated indole ester 72a-e in the presence of $5 \mathrm{~mol} \% \mathrm{Cu}(\mathrm{OTf})_{2}$ afford pyrroloindoles $\mathbf{7 3 a}-\mathbf{j}$ and $74 a-j$ in excellent overall yields of $85-92 \%$ with outstanding regio- and diastereoselectivity ${ }^{53}$ (Scheme 28).

The ester moiety in case of 72 is crucial in controlling diastereoselectivity in these cycloadditions. Other Lewis acid catalysts such as $\mathrm{TiCl}_{4}, \mathrm{BF}_{3}-\mathrm{Et}_{2} \mathrm{O}, \mathrm{FeCl}_{3}, \mathrm{AlCl}_{3}, \mathrm{Sn}(\mathrm{OTf})_{2}$ and $\mathrm{Fe}(\mathrm{OTf})_{3}$ have resulted in poor diastereoselectivity of $11: 1$, $14: 1,4: 1,3: 1,7: 1$ and $6: 1$ for products $73 / 74$. The methodology has also been used for the construction of the fully functionalized tricyclic core of bioactive natural product yuremamine which has been isolated from the stem bark of
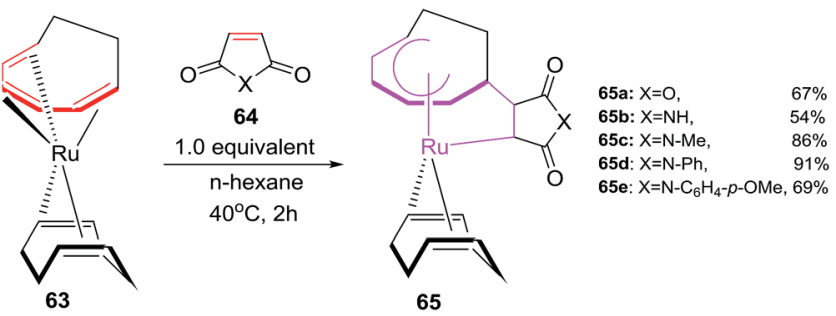

Scheme 26 Formation of ruthenacycles 67 via oxidative cyclisations. 


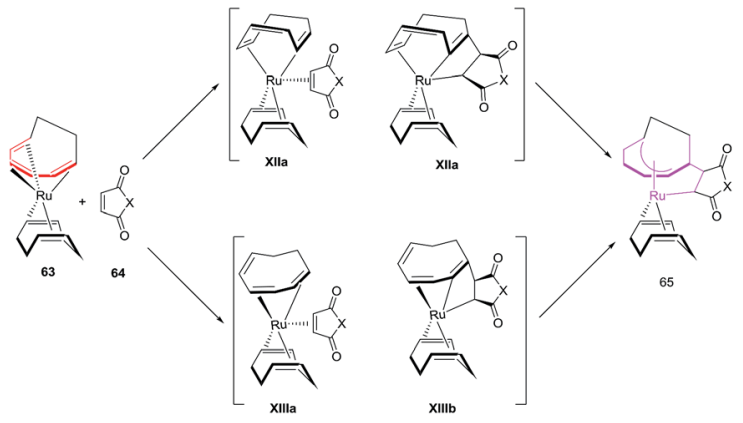

Fig. 10 Proposed mechanism for formation of ruthenacycles 65.

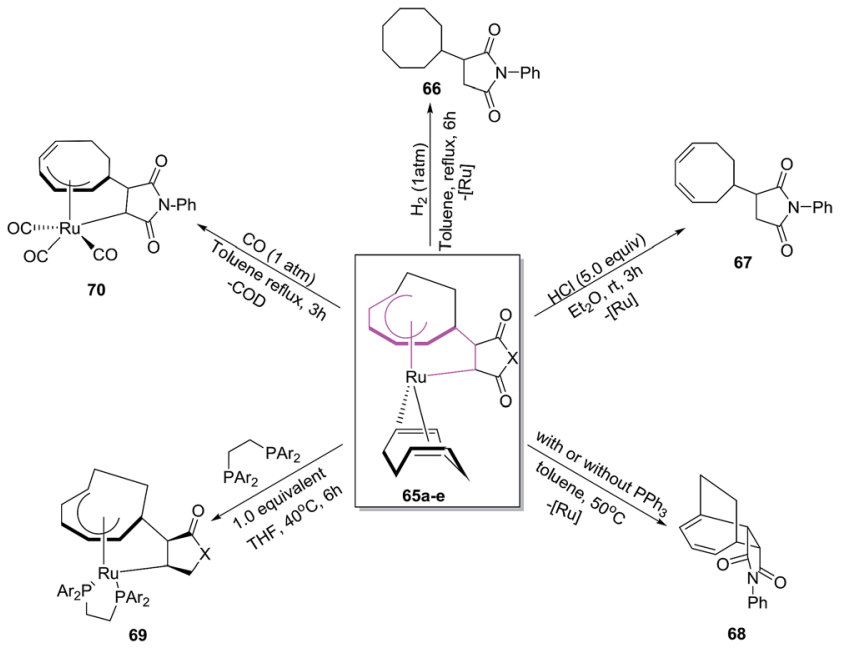

Scheme 27 Reactivity of ruthenacycle 65

Mimosa hostilis having hallucinogenic and psychoactive effects ${ }^{54}$ (Fig. 11).

\section{Chromium catalysed $[6+2]$ cycloaddition reactions}

Chromium(0) complexes are also been tested in $[6+2]$ cycloadditions and a single report on $\operatorname{Cr}(0)$ catalysed $[6+2]$ cycloadditions is disclosed by Rigby et al. It involves the development of resin supported chromium(0) catalytic system and their use as catalyst in $[6+2]$ cycloadditions of cycloheptatriene (CHT) with variety of alkenes. The resin based chromium catalyst

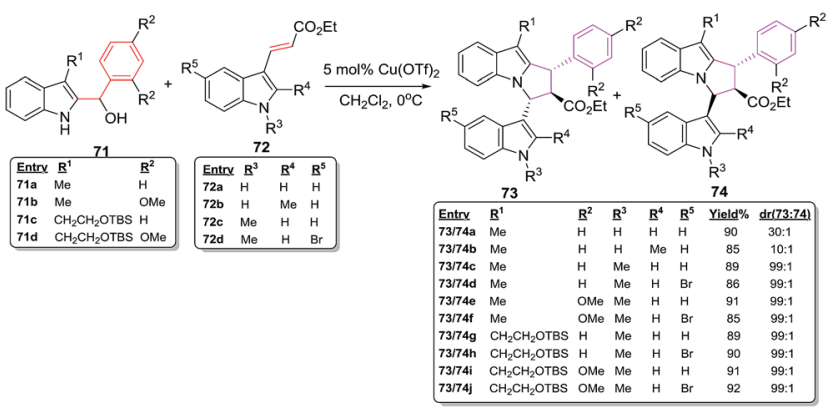

Scheme $28 \mathrm{Cu}(\mathrm{OTf})_{2}$ catalysed [6 + 2] cycloadditions reactions of 71 and 72 .

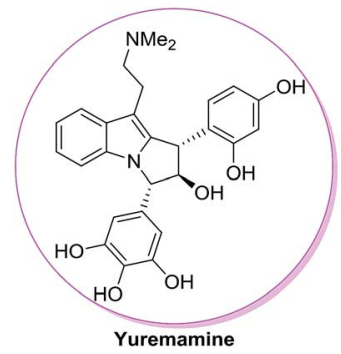

Fig. 11 Structure of yuremamine.
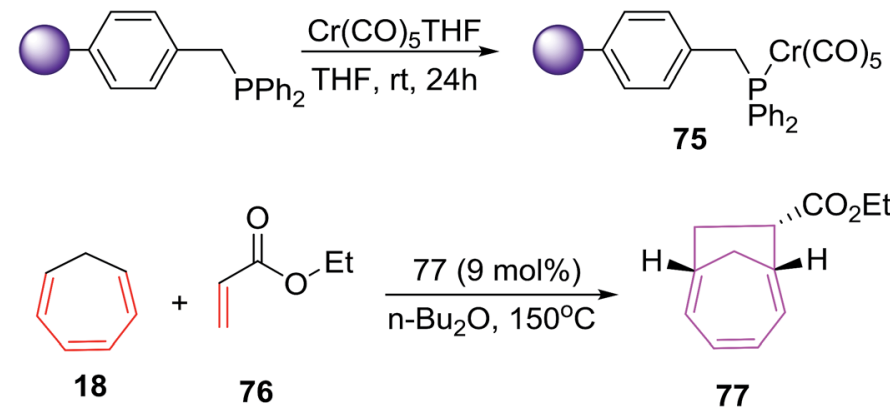

Scheme $29[6+2]$ cycloadditions of $\mathrm{CHT}$ with ethyl acrylate catalysed by solid supported chromium(0) complex.

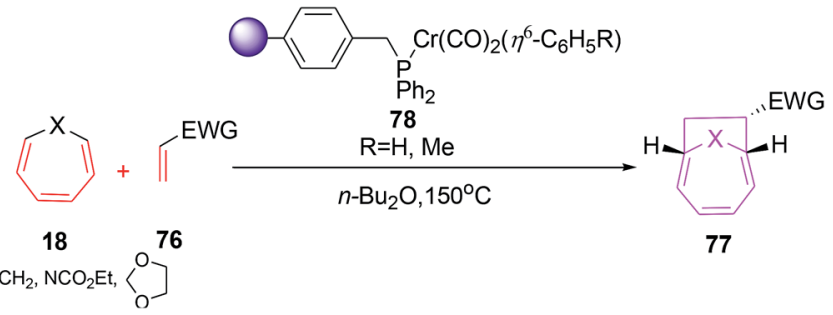

Scheme $30 \quad[6+2]$ cycloadditions of CHT with ethyl acrylate catalysed by solid supported chromium(0) complex.

prepared from chloromethylated polystyrene (PS-DVB) (Merrifield resin, $2 \%$ cross linked) 75 (9 mol\%) catalyses the $[6+2]$ cycloadditions of CHT 18 with excess ethyl acrylate 76 to afford bicyclo[4.2.1]nona-2,4-diene 77 in 59\% yield. However, the catalytic system has a serious drawback of recyclability owing to thermal denaturation of the catalytic systems (Scheme 29).

Replacing chromium coordination sphere to $\eta^{6}-\mathrm{C}_{6} \mathrm{H}_{5}$ has marked effect on its multiple recyclability by simple filtration followed by washing with non polar solvents (Scheme 30). ${ }^{55}$ The catalyst 78 affords $[6+2]$ cycloadditions in excellent yield (6492\%) in the reactions of CHT 18 with various electron rich trienophiles. ${ }^{56}$

\section{Conclusion}

In conclusion, the present review summarises transition metal catalysed $[6+2]$ cycloaddition reactions that have appeared in literature since 2000. Various inter and intramolecular versions have been explored employing various substrates contributing 
as $6 \pi$ component promoted by different transition metal catalysts. The developed methodologies have provided a facile access to mono- and bicyclic carbo-/heterocyclic eight membered core structures which are otherwise difficult to achieve. Although, the developed protocols have provided an informal to functionalised ring systems, but, the true potential of $[6+2]$ cycloadditions still need to be scrutinized so as to access its regio and stereselective versions under milder reaction conditions. Copper, ruthenium, chromium and platinum based complexes have made entry to the list of metals catalysed $[6+2]$ cycloadditions, but the detailed studies on such metals catalysed $[6+2]$ cycloaddition involving other prevalent substrates as $6 \pi$ components still need to be explored. Moreover, the semicyclic variants of $6 \pi$ components in transition metal catalysed still need to be studied. The studies on $[6+2]$ cycloadditions involving different heterodienophiles also need to be explored. Hence, $[6+2]$ cycloadditions have an enormous potential for the synthesis of eight membered monocyclic or fused heterocyclic systems.

The authors have tried to recapitulate most of the reports appearing within the stipulated time frame, nonetheless there will always be some experts missing for which we deeply apologize.

\section{Conflicts of interest}

There are no conflicts to declare.

\section{Notes and references}

1 (a) Advances in Cycloaddition, ed. D. P. Curran, JAI Press, Greenwich, 1994, vol. 1-3; (b) B. M. Trost, Angew. Chem., Int. Ed. Engl., 1995, 34, 259; (c) M. Lautens, W. Klute and W. Tam, Chem. Rev., 1996, 96, 49; (d) N. E. Schore, Chem. Rev., 1988, 88, 1081.

2 (a) B. M. Trost, Acc. Chem. Res., 2002, 35, 695; (b) M. Dai, D. Sarlah, M. Yu, S. J. Danishefsky, G. O. Jones and K. N. Houk, J. Am. Chem. Soc., 2007, 129, 645.

3 E. J. Corey, N. M. Weinshnker, T. K. Schaaf and W. J. Huber, J. Am. Chem. Soc., 1969, 91, 5675.

$4[5+2]$ cycloaddition references see: H. Pellissiera, Adv. Synth. Catal., 2011, 353, 189 and reference cited therein.

5 (a) For [6+2] cycloadditions see: X. Z. Yu, Y. Wang and Y. Wang, Chem.-Asian J., 2010, 5, 1072 and reference cited therein; (b) For a review on [8+2] cycloadditions, see: V. Nair and K. G. Abhilash, Synlett, 2008, 301.

6 (a) D. J. Faulkner, Nat. Prod. Rep., 1988, 5, 613; (b) D. G. I. Kingston, J. Org. Chem., 2008, 73, 3975; (c) R. S. Daum, S. Kar and P. Kirkpatrick, Nat. Rev. Drug Discovery, 2007, 6, 865.

7 For pleuromutilin, see: P. Brown and M. Dawson, Prog. Med. Chem., 2015, 54, 135 and reference cited therein.

8 Z. -K. Yao, J. Li and Z.-X. Yu, Org. Lett., 2011, 13, 134.

9 For Rh(I)-catalysed intramolecular [6+2] cycloadditions, see: (a) P. A. Wender, A. G. Correa, Y. Sato and R. Sun, J. Am. Chem. Soc., 2000, 122, 7815; (b) F. Inagaki, K. Sugikubo, Y. Oura and C. Mukai, Chem.-Eur. J., 2011, 17, 9062; (c)
Y. Oonishi, A. Hosotani and Y. Sato, J. Am. Chem. Soc., 2011, 133, 10386.

10 For Rh(I)-catalyzed [5+2+1] cycloadditions, see: (a) P. A. Wender, G. G. Gamber, R. D. Hubbard and L. Zhang, J. Am. Chem. Soc., 2002, 124, 2876; (b) H. A. Wegner, A. de Meijere and P. A. Wender, J. Am. Chem. Soc., 2005, 127, 6530; (c) Y. Wang, J. Wang, J. Su, F. Huang, L. Jiao, Y. Liang, D. Yang, S. Zhang, P. A. Wender and Z.-X. Yu, J. Am. Chem. Soc., 2007, 129, 10060; (d) F. Huang, Z.-K. Yao, Y. Wang, J. Zhang and Z.-X. Yu, Chem.-Asian J., 2010, 5, 1555. 11 For $\mathrm{Rh}(\mathrm{I})$-catalyzed $[4+2+2]$ cycloadditions, see (a) P. A. Evans, J. E. Robinson, E. W. Baum and A. N. Fazal, J. Am. Chem. Soc., 2002, 124, 8782; (b) S. R. Gilbertson and B. J. DeBoef, J. Am. Chem. Soc., 2002, 124, 8784; (c) P. A. Evans and E. W. Baum, J. Am. Chem. Soc., 2004, 126, 11150; (d) P. A. Evans, E. W. Baum, A. N. Fazal and M. Pink, Chem. Commun., 2005, 63; (e) P. A. Wender and J. P. Christy, J. Am. Chem. Soc., 2006, 128, 5354; (f) B. DeBoef, W. R. Counts and S. R. Gilbertson, J. Org. Chem., 2007, 72, 799.

12 For the synthesis of a monocyclic eight-membered ring by $\mathrm{Rh}(\mathrm{I})$ catalyzed hydroacylation, see (a) A. D. Aloise, M. E. Layton and M. D. Shair, J. Am. Chem. Soc., 2000, 122, 12610; (b) D. Crepin, J. Dawick and C. Aissa, Angew. Chem., 2010, 122, 630; Angew. Chem. Int. Ed., 2010, 49, 620.

13 (a) M. E. Maier, Angew. Chem., 2000, 112, 2153; Angew. Chem., Int. Ed., 2000, 39, 2073; (b) A. Michaut and J. Rodriguez, Angew. Chem., 2006, 118, 5870; Angew. Chem., Int. Ed., 2006, 45, 5740; (c) For an exampleof applying Cope rearrangement in total synthesis of natural product asteriscanolide, see: J. Limanto and M. L. Snapper, J. Am. Chem. Soc., 2000, 122, 8071.

14 For uncatalysed [6+2] cycloadditions since year 2000, which are not covered in the current article, see: $(a)$ O. Yahiaoui, L. F. Pasteka, B. Judeel and T. Fallon, Angew. Chem., Int. Ed., 2018, 57, 2570; (b) Z. Wang, Y. Addepalli and Y. He, Org. Lett., 2018, 20, 644; (c) R. Hanada, K. Mitachi and K. Tanino, Tetrahedron Lett., 2014, 55, 1097; (d) N. Coskun, J. Maa, A. Saeed, C. Gartner and I. Erden, Org. Lett., 2011, 13, 5952; (e) S. Koya, K. Yamanoi, R. Yamasaki, I. Azumaya, H. Masu and S. Saito, Org. Lett., 2009, 11, 5438; (f) T. Sugimura, C.-Y. Im and T. Okuyama, Tetrahedron Lett., 2004, 45, 1519; $(g)$ B.-C. Hong, Y.-J. Shr, J.-L. Wu, A. K. Gupta and K.-J. Lin, Org. Lett., 2002, 4, 2249; $(h)$ K. Takaoka, T. Aoyama and T. Shioiri, Heterocycles, 2001, 54, 209.

15 For selected examples: (a) J. J. Wang and J. H. Wang, Angew. Chem., Int. Ed., 2012, 51, 12334; (b) P. Metza, Adv. Synth. Catal., 2009, 351, 3128; (c) J. R. Kong, C. W. Cho and M. J. Krische, J. Am. Chem. Soc., 2005, 127, 11269; (d) M. E. Vander Boom and D. Milstein, Chem. Rev., 2003, 103, 1759; (e) C. H. Jun, Chem. Soc. Rev., 2004, 33, 610; $(f)$ D. Nečas and M. Kotora, Curr. Org. Chem., 2007, 11, 1566; (g) M. Tobisu and N. Chatani, Chem. Soc. Rev., 2008, 37, 300; (h) S. M. Bonesi and M. Fagnoni, Chem.-Eur. J., 2010, 16, 13572. 
16 For selected examples: (a) S. Hashimotoa, Tetrahedron Lett., 2009, 50, 3675; (b) S. Shin, A. K. Gupta and C. Y. Rhim, Chem. Commun., 2005, 35, 4429; (c) A. J. Padwa, J. Org. Chem., 1995, 60, 6258.

17 (a) C. S. Bryan and M. Lautens, Org. Lett., 2008, 10, 4633; (b) M. Lautens and J. Mancuso, Org. Lett., 2002, 4, 2105; (c) M. Lautens and M. Yoshida, Org. Lett., 2002, 4, 123; (d) J. L. Mascareñas and G. Saya, Angew. Chem., 2010, 122, 10082; (e) J. L. Mascareñas, G. Bhargava, B. Trillo and M. Araya, Chem. Commun., 2010, 46, 270; $(f)$ K. Teruyuki, Molecules, 2010, 15, 4189; ( $g$ ) A. Padwa and D. B. England, J. Org. Chem., 2008, 73, 2792; (h) J. M. Mejia-Oneto and A. Padwa, Org. Lett., 2006, 8, 3275; (i) A. Padwa, J. Boonsombat, P. Rashatasakhon and J. Willis, Org. Lett., 2005, 7, 3725; (j) P. A. Evans, J. E. Robinson, E. W. Baum and A. N. Fazal, J. Am. Chem. Soc., 2002, 124, 8782; $(k)$ S. R. Gilbertson and B. DeBoef, J. Am. Chem. Soc., 2002, 124, 8784; (l) T. Fukuyama, Y. Ohta, C. Brancour, K. Miyagawa, I. Ryu, A. L. Dhimane, L. Fensterbank and M. Malacria, Chem.-Eur. J., 2012, 18, 7243; $(\mathrm{m}) \mathrm{Z}$. X. Yu, Y. A. Guo, G. Y. Kang and M. Lin, J. Am. Chem. Soc., 2012, 134, 398.

18 P. A. Wender, A. G. Correa, Y. Sato and R. Sun, J. Am. Chem. Soc., 2000, 122, 7815.

19 Y. Oonishi, A. Hosotani and Y. Sato, J. Am. Chem. Soc., 2011, 133, 10386.

20 Y. Oonishi, A. Hosotani and Y. Sato, Angew. Chem., Int. Ed., 2012, 51, 11548.

21 F. Inagaki, K. Sugikubo, Y. Miyashita and C. Mukai, Angew. Chem., 2010, 122, 2252; Angew. Chem., Int. Ed., 2010, 49, 2206.

22 F. Inagaki, K. Sugikubo, Y. Oura and C. Mukai, Chem.-Eur. J., 2011, 17, 9062.

23 (a) Z. X. Yu, P. A. Wender and K. N. Houk, J. Am. Chem. Soc., 2004, 126, 9154; (b) Z. X. Yu, P. H. Y. Cheong, P. Liu, C. Y. Legault, P. A. Wender and K. N. Houk, J. Am. Chem. Soc., 2008, 130, 2378; (c) P. Liu, H. Y. Cheong, Z. X. Yu, P. A. Wender and K. N. Houk, Angew. Chem., 2008, 120, 4003; Angew. Chem., Int. Ed., 2008, 47, 3939; (d) P. Liu, L. E. Siros, P. H. Y. Cheong, Z. X. Yu, I. V. Hartung, H. Rieck, P. A. Wender and K. N. Houk, J. Am. Chem. Soc., 2010, 132, 10127.

24 P. A. Wender, N. M. Deschamps and R. Sun, Angew. Chem., 2006, 118, 4061; Angew. Chem., Int. Ed., 2006, 45, 3957.

25 M. R. Siebert, J. M. Osbourn, K. M. Brummond and D. J. Tantillo, J. Am. Chem. Soc., 2010, 132, 11952.

$26 \mathrm{Ti}$ catalyzed reactions: (a) K. Mach, H. Antropiusová, P. Sedmera, V. Hanuš and F. Tureček, J. Chem. Soc., Chem. Commun., 1983, 805; (b) K. Mach, H. Antropiusová, L. Petrusová, V. Hanuš, F. Tureček and P. Sedmera, Tetrahedron, 1984, 40, 3295; (c) R. Klein, P. Sedmera, J. Cÿejka and K. Mach, J. Organomet. Chem., 1992, 436, 143. $27 \mathrm{Ru}$ catalyzed reactions: (a) M. Green, S. M. Heathcock, T. W. Turney and D. M. P. Mingos, J. Chem. Soc., Dalton Trans., 1977, 204; (b) K. Itoh, K. Mukai, H. Nagashima and H. Nishiyama, Chem. Lett., 1983, 499; (c) H. Nagashima, H. Matsuda and K. Itoh, J. Organomet. Chem., 1983, 258, C15.
28 Mo mediated reactions: (a) D. G. Bourner, L. Brammer, M. Green, G. Moran, A. G. Orpen, C. Reeve and C. J. Schaverien, J. Chem. Soc., Chem. Commun., 1985, 1409; (b) T. Schmidt, F. Bienewald and R. Goddard, J. Chem. Soc., Chem. Commun., 1994, 1857.

29 Co catalysed cyclotrimerizations of alkynes: (a) A. Geny, N. Agenet, L. annazzo, M. Malacria, C. Aubert and V. Gandon, Angew. Chem., Int. Ed., 2009, 48, 1810; (b) G. Hilt, C. Hengst and W. Hess, Eur. J. Org. Chem., 2008, 2293; (c) G. Hilt, T. Vogler, W. Hess and F. Galbiati, Chem. Commun., 2005, 1474; (d) L. Doszczak, P. Fey and R. Tacke, Synlett, 2007, 753; (e) H. T. Chang, M. Jeganmohan and C. H. Cheng, Org. Lett., 2007, 9, 505; (f) N. Saino, F. Amemiya, E. Tanabe, K. Kase and S. Okamoto, Org. Lett., 2006, 8, 1439; $(g)$ M. S. Wu, M. Shanmugasundaram and C. H. Cheng, Chem. Commun., 2003, 718; $(h)$ L. Yong and H. Butenschön, Chem. Commun., 2002, 2852; (i) T. A. Sugihara, Wakabayashi, Y. Nagai, H. Takao, H. Imagawa and M. Nishizawa, Chem. Commun., 2002, 576; (j) J. H. Rigby, M. S. Laxmisha, A. R. Hudson, C. H. Heap and M. J. Heeg, J. Org. Chem., 2004, 69, 6751.

30 (a) J. H. Rigby, K. M. Short, H. S. Ateeq and J. A. Henshilwood, J. Org. Chem., 1992, 57, 5290; (b) J. H. Rigby, H. S. Ateeq, N. R. Charles, J. A. Henshilwood, K. M. Short and P. M. Sugathapala, Tetrahedron, 1993, 49, 5495; (c) J. H. Rigby, M. A. Kondratenko and C. Fiedler, Org. Lett., 2000, 2, 3917; (d) J. H. Rigby, L. M. Mann and B. J. Myers, Tetrahedron Lett., 2001, 42, 8773; (e) C. G. Kreiter, E. Michels and H. Kurz, J. Organomet. Chem., 1982, 232, 249.

31 (a) J. S. Ward and R. Pettit, J. Am. Chem. Soc., 1971, 93, 262; (b) M. Green, S. M. Heathcock, T. W. Turney and D. M. P. Mingos, J. Chem. Soc., Dalton Trans., 1977, 204; (c) A. J. Pearson and X. Wang, Tetrahedron Lett., 2005, 46, 3123. 32 See ref. $26 a$ and $b$ J. F. Kaagman, M. Rep, M. Horacek, P. Sedmera, J. Cejka, V. Varga and K. Mach, Collect. Czech. Chem. Commun., 1996, 61, 1722. and references therein.

33 (a) N. Toselli, D. Martin, M. Achard, A. Tenaglia, T. Bürgi and G. Buono, Adv. Synth. Catal., 2008, 350, 280; (b) M. Achard, M. Mosrin, A. Tenaglia and G. Buono, J. Org. Chem., 2006, 71, 2907; (c) M. Achard, A. Tenaglia and G. Buono, Org. Lett., 2005, 7, 2353.

34 M. Achard, M. Mosrin, A. Tenaglia and G. Buono, J. Org. Chem., 2006, 71, 2907.

35 H. Clavier, K. L. Jeune and G. Buono, Org. Lett., 2011, 13, 308. 36 X. Zhang, J. Wang, H. Zhao, H. Zhao and J. Wang, Organometallics, 2013, 32, 3529-3536.

37 D. B. Ramachary and V. V. Narayana, Eur. J. Org. Chem., 2011, 3514.

38 M. Achard, A. Tenaglia and G. Buono, Org. Lett., 2005, 7, 2353.

39 (a) O. Pardigon and G. Buono, Tetrahedron: Asymmetry, 1993, 4, 1977; (b) O. Pardigon, A. Tenaglia and G. Buono, J. Org. Chem., 1995, 60, 1868; (c) A. Tenaglia, O. Pardigon and G. Buono, J. Org. Chem., 1996, 61, 1129; (d) O. Pardigon, A. Tenaglia and G. Buono, J. Mol. Catal. A: Chem., 2003, 196, 157; (e) G. Hilt and K. I. Smolko, Synthesis, 2002, 5, 
686; $(f)$ I. F. Duan, C. H. Cheng, J. S. Shaw, S. S. Cheng and K. F. Liou, J. Chem. Soc., Chem. Commun., 1991, 1347; $(g)$ M. S. Wu, M. Shanmugasundaram and C. H. Cheng, $J$. Chem. Soc., Chem. Commun., 2003, 718; (h) P. Binger and S. J. Albus, Organomet. Chem., 1995, 493, C6-C8; (i) $[4+2+$ 2] cycloaddition of norbornadiene with 1,3-dienes, see: ; $(j)$ Y. Chen, R. Kiattansakul, B. Ma and J. Snyder, J. Org. Chem., 2001, 66, 6932; $(k)$ B. Ma and J. K. Snyder, Organometallics, 2002, 21, 4688; $(l)$ G. Hilt and K. I. Smolko, Angew. Chem., Int. Ed., 2003, 42, 2795; $(m)$ G. Hilt, K. I. Smolko and B. V. Lotsch, Synlett, 2002, 7, 1081. 40 H. Clavier, K. L. Jeune, I. D. Riggi, A. Tenaglia and G. Buono, Org. Lett., 2011, 13, 308-311.

41 V. A. D'yakonov, G. N. Kadikova, G. F. Gazizullina, L. M. Khalilov and U. M. Dzhemilev, Tetrahedron Lett., 2015, 56, 2005.

42 M. Achard, M. Mosrin, A. Tenaglia and G. Buono, J. Org. Chem., 2006, 71, 2907.

43 K. Mitachi, T. Shimizu, M. Miyashita and K. Tanino, Tetrahedron Lett., 2010, 51, 3983.

44 T. Jeffery, Tetrahedron Lett., 1989, 30, 2225.

45 R. Hanada, K. Mitachi and K. Tanino, Tetrahedron Lett., 2014, 55, 1097.

46 V. A. D'yakonov, G. N. Kadikova, D. I. Kolokol'tsev, I. R. Ramazanov and U. M. Dzhemilev, J. Organomet. Chem., 2015, 794, 23.
47 V. A. D'yakonov, G. N. Kadikova, D. I. Kolokol'tsev, I. R. Ramazanov and U. M. Dzhemilev, Eur. J. Org. Chem., 2015, 4464.

48 V. A. D'yakonov, G. N. Kadikova, R. N. Nasretdinov, D. I. Kolokol'tsev and U. M. Dzhemilev, Tetrahedron Lett., 2017, 58, 1839.

49 S. Tenaglia and S. Gaillard, Angew. Chem., Int. Ed., 2008, 47, 2454.

50 Y. Ura, T. Utsumi, H. Tsujita, K. Weda, T. Kondo and T. Mitsudo, Organometallics, 2006, 25, 2934-2942.

51 T. Mitsudo, T. Suzuki, S. W. Zhang, D. Imai, K. Fujita, T. Manabe, M. Shiotsuki, Y. Wantanbe, K. Wada and T. Kondo, J. Am. Chem. Soc., 1999, 121, 1839.

52 K. Itoh, K. Mukai, H. Nagashima and H. Nishiyama, Chem. Lett., 1983, 499.

53 D. Dethe, R. Boda and S. Das, Chem. Commun., 2013, 49, 3260.

54 J. J. Vepsalainen, S. Auriola, M. Tukianen, N. ropponen and J. C. Callaway, Planta Med., 2005, 71, 1053.

55 J. H. Rigby, M. A. Kondratenko and C. Fiedler, Org. Lett., 2000, 24, 3917.

56 J. A. S. Howell, M. G. Palin, P. McArdle, D. Cunningham, Z. Goldschmidt, H. E. Gottlieb and D. Herzoni-Langerman, Organometallics, 1993, 12, 1694. 